\title{
Regulation of Dopamine D1 Receptor Signaling at the Golgi Apparatus by a Low Affinity Dopamine Transporter
}

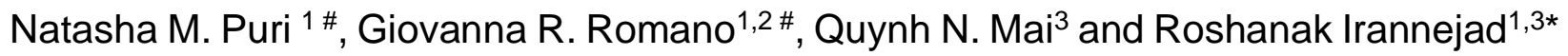
${ }^{1}$ Department of Biochemistry \& Biophysics, University of California, San Francisco, USA, Biochemistry Department, Weill Cornell Medicine, USA, ${ }^{3}$ Cardiovascular Research Institute, University of California, San Francisco, USA,

\#These authors contributed equally

${ }^{*}$ Corresponding author

\begin{abstract}
Dopamine is the main catecholamine in the brain and the kidney, where it controls a number of physiological functions such as locomotion, cognition, emotion, endocrine regulation and renal function. As a membrane impermeant hormone and neurotransmitter, dopamine is thought to relay its signaling function by binding and activating dopamine receptors, members of the G protein couple receptors (GPCRs) family, only on the plasma membrane. Here, using novel nanobody-based biosensors, we demonstrate for the first time that the dopamine D1 receptor (D1DR), the primary mediator of dopaminergic signaling in the brain and kidney, not only functions on the plasma membrane but becomes activated at the Golgi apparatus upon the presence of its ligand. We present evidence that activation of the Golgi pool of D1DR is dependent on Organic Cation Transporter 2 (OCT2), a low affinity dopamine transporter, providing an explanation for how the membrane impermeant dopamine accesses subcellular pools of D1DR. We also introduce a new approach to selectively interrogate compartmentalized D1DR signaling by inhibiting Gas coupling, using a nanobody-based chemical recruitment system. Using this strategy, we show that Golgi-localized D1DRs regulate cAMP production and mediate local protein kinase A activation. Together, our data suggest that spatially compartmentalized signaling hubs are previously unappreciated regulatory aspects of D1DR signaling. Our data also provide further evidence for the role of transporters in regulating subcellular GPCR activity.
\end{abstract}

\section{Introduction}

Dopamine (DA) is a major hormone and neurotransmitter that regulates a wide range of physiological responses, for example reward-motivated behavior and motor control in the CNS as well as sodium secretion in the kidney (1). All cellular actions of DA are mediated by Dopamine receptors, a class of GPCR. Several pathological conditions such as Parkinson's disease, schizophrenia and addiction are due to dysregulation of the neuronal dopaminergic signaling pathway, while hypertension has been attributed to impaired renal dopaminergic signaling. Dopamine receptor antagonists have been developed with the goal of blocking hallucinations and delusions that occur in schizophrenic patients, whereas DA receptor agonists are used to alleviate the moving defects of Parkinson's disease (2-4).

In both the central nervous system (CNS) and the kidney, DA is produced locally. There are five subtypes of Dopamine receptors, D1, D2, D3, D4 and D5, that are classified as 
D1-class receptors (D1 and D5) or D2-class receptors (D2, D3 and D4) $(5,6)$. The D1class (D1 and D5 receptors) are primarily coupled to Gas/olf proteins and stimulate the activity of adenylyl cyclase, AC, leading to the production of the second messenger cyclic AMP, cAMP (7). In contrast, the D2 class (D2S, D2L, D3 and D4 receptors) are associated with Gai/o proteins and inhibit cAMP production (7). D1 Dopamine Receptors (D1DRs) are highly expressed in the CNS where they underlie major brain functions such as locomotion, learning and memory, attention, impulse control, and sleep (1). Additionally, D1DRs in the kidney regulate trafficking of sodium ATPase and transporters, thereby affecting renal function $(8,9)$.

Impermeable agonists such as DA have been thought for a long time to activate D1DR only at the plasma membrane. Like many GPCRs, receptor removal from the cell surface by endocytosis has been described as a mechanism that attenuates cellular signaling (10-12). However, evidence from the past decade suggests that for some GPCRs endocytosis might in fact activate a second phase of acute or prolonged Gas-mediated cAMP response from the endosomes (13-23). Recent studies further support this notion by providing evidence that CAMP generation by activated receptors at the endosome are necessary in regulating transcriptional responses that are distinct from those elicited by activation of the plasma membrane receptor pool (24-28).

Most of the receptors that have been shown to exhibit a second phase of signaling from internal compartments are primarily coupled to Gas protein. cAMP diffusion is within the nanometer scale around phosphodiesterases at physiological conditions $(29,30)$. Given this narrow range of diffusion, it has been difficult to explain how receptor activation solely on the plasma membrane results in the activation of downstream effectors at distant subcellular locations such as the endoplasmic reticulum, Golgi and the nucleus (30-32). As one explanation for this observation, we recently showed that activation of the Golgilocalized beta1 adrenergic receptors $(\beta 1 \mathrm{AR})$ cause local production of cAMP by Golgi localized Gas protein. Importantly, we demonstrated that a catecholamine transporter facilitates the transport of epinephrine, a membrane impermeant endogenous $\beta 1 A R$ agonist, to the lumen of the Golgi and activates the Golgi pool of $\beta 1 A R$. The importance of generation of local pool of cAMP by Golgi-localized $\beta 1$ AR was further supported by the fact that activated Golgi- $\beta 1 \mathrm{ARs}$ only, but not the plasma membrane pool, lead to PLC $\varepsilon$ activation at the perinuclear/Golgi membrane, which mediates hypertrophic responses in cardiomyocytes $(33,34)$.

Whether the need for local cAMP generation is unique to cell types or specific GPCRs is not well understood. The lack of cAMP mobility in cells becomes prominent in larger cells with higher membrane compartmentation, which will further create physical barriers for cAMP diffusion. Considering the high degree of membrane compartmentation of neurons and proximal tubules of the kidney, the two main cells types that express D1DRs, we wondered whether D1DR signaling is also compartmentalized. Here, using a conformational sensitive nanobody that recognizes activated D1DR, we show that the pre-existing pool of D1DR that is localized to the Golgi membrane is activated upon stimulation with extracellular DA. Furthermore, we demonstrate that a low affinity dopamine transporter, an Organic Cation Transporter (OCT2), facilitates the transport of 
DA to the Golgi-localized D1DR and regulates its local activity at the Golgi. We further show that OCT2 has a distinct expression pattern in the kidney and specific regions of the brain, where D1DRs are endogenously expressed. Our findings thus identify a novel role for a monoamine transporter in regulating a specific pool of the D1DRs and their function in a physiologically relevant model of dopaminergic signaling.

\section{Results}

Nanobody-based conformational sensitive biosensors detect active D1DR and Gs protein at subcellular membranes. We have previously shown that a single-domain cameloid antibody, nanobody 80 ( $\mathrm{Nb80)}$ ), originally developed to stabilize an active conformation of beta 2 adrenergic receptor ( $\beta 2 A R$ ) for crystallography purposes (35), can be repurposed as a conformational biosensor to detect activated $\beta 2 A R$ and $\beta 1 A R$ in living cells $(17,33)$. Through directed evolution on Nb80, a high-affinity nanobody (Nb6B9) was generated that stabilizes the active conformation of epinephrine bound $\beta 2 A R$ (36). Given that $\beta 2 \mathrm{AR} / \mathrm{Nb} 6 \mathrm{~B} 9$ binding sites are highly conserved among other aminergic receptors such as $\beta 1 A R$ and D1DR (Supplementary Figure 1)(35), we reasoned that this nanobody could also be used as a conformational sensitive biosensor to detect activated D1DR in real time and in living cells (Figure 1a). In HeLa cells expressing Snap-tagged D1DR, Nb6B9 fused to GFP (Nb6B9-GFP) was diffuse throughout the cytoplasm (Figure 1b,

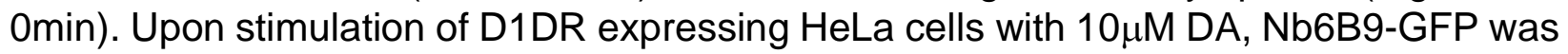
rapidly recruited first to the plasma membrane and shortly after to the Golgi apparatus (Figure 1b, 2min, Supplementary Movie 1). This data suggests that the D1DR Golgi pool is activated in response to extracellular DA addition. Interestingly, stimulation of $10 \mu \mathrm{M} D A$ in HEK293 cells expressing D1DR resulted in the recruitment of NB6B9-GFP only at the plasma membrane (Figure 1b, lower panel, 2min, Supplementary Movie 2). However, in both cell types, SKF81297, a selective membrane permeant D1DR agonist, activated both receptor pools (Supplementary Figure 2 and Supplementary movie 3 and 4). In addition to the Golgi recruitment and consistent with a previous report (16), Nb6B9 was also found to colocalize with D1DR at the endosomes, at a later time after agonist addition, indicating an active pool of D1DR at endosomes (Supplementary Movie 2). We further used mini-Gs protein, a more general biosensor for Gs-coupled GPCRs (37), to show that the active pool of D1DR at the plasma membrane, endosomes, and the Golgi can also be detected by mini-Gs recruitment to these locations (Supplementary Figure 3).

To investigate whether activated D1DR can couple to G protein and elicit a G-protein mediated response at the Golgi, we took advantage of another nanobody-based biosensor, Nb37-GFP. We previously used Nb37-GFP to detect transiently active $\beta 1 \mathrm{AR} / \mathrm{Gs}$ and $\beta 2 \mathrm{AR} / \mathrm{Gs}$ complexes at the Golgi and endosomes, respectively $(17,33)$. Similar to what we previously observed with $\beta 1 \mathrm{AR}, \mathrm{Nb37}$ was recruited to the plasma membrane and the Golgi upon stimulation with DA, suggesting that the D1DR Golgi pool is able to couple to $G$ protein and activate it (Supplementary Figure $4 b$ and c). Together, these findings suggest a distinct spatiotemporal regulation of D1DR signaling at the plasma membrane and the Golgi membranes.

OCT2 facilitates the transport of Dopamine to the Golgi-localized D1DR. 
These observations raised the key question of how DA, a hydrophilic/membrane impermeant monoamine, can access the Golgi pool of D1DR. The first clue came from the observation that DA can activate Golgi-D1DR in HeLa cells but not HEK293 cells (Figure 1b, Supplementary Movie 1 and 2) whereas SKF81297, a hydrophobic/membrane permeant agonist, can activate the Golgi pool of D1DR in both cell types (Supplementary Figure 2, Supplementary Movie 3 and 4). These differential effects of DA and SKF81297 are not based on their differential potency for activating D1DR, as they have comparative EC50 values in inducing cAMP responses (Figure 2a). Moreover, D1DR activation at the Golgi was not dependent on receptor internalization, as inhibiting endocytosis by blocking dynamin did not block D1DR activation at the Golgi (Supplementary Figure 4a and c). We previously found that a membrane transporter, Organic Cation Transporters 3 (OCT3), facilitates epinephrine transport resulting in activation of the Golgi-localized $\beta 1 A R$. OCT3 is a member of the solute carrier (SLC) family 22, electrogenic and bidirectional catecholamine transporters that are localized on the plasma membrane and intracellular compartments (33). Therefore, we hypothesized that another OCT family transporter can similarly function in DA transport to allow for the activation of Golgi-localized D1DR pools.

There are three main OCTs that have largely overlapping distribution but distinct substrates. OCT3 facilitates the transport of epinephrine and norepinephrine (38). DA has been identified as a key endogenous substrate for another member of the SLC22A family, OCT2 (SLC22A2)(39-42). We thus asked whether OCT2 has a role in transporting DA to the Golgi membranes. OCT2 showed significant protein expression in HeLa cells as measured by western blotting, whereas no significant expression was detected in HEK293 cells (Figure 2b). To test the role of OCT2 in DA transport, we then overexpressed OCT2-mApple in HEK293 cells and used Nb6B9-GFP to assess D1DR activation in live cells. By overexpressing OCT2-mApple in HEK293 cells, we found that Nb6B9-GFP could now be recruited to activated D1DR at the Golgi. (Figure 2c and d, Supplementary Movie 5). These results suggest that OCT2 can facilitate the transport of DA to the Golgi lumen where it then activates D1DR at the Golgi membranes.

To investigate the role of OCT2 in D1DR signaling in physiologically relevant cell types, we measured OCT2 expression patterns in two main organs where D1DR are known to express and have function, the kidney and the brain. We found that OCT2 is highly expressed in the kidney and has a distinct expression pattern in different regions of the brain. OCT2 is highly expressed in the striatum and cortex, where D1DR is known to express and have function. However, OCT2 expression was negligible in the hippocampus and substantia nigra, another region where D1DR has known functions (Supplementary Figure 5a-c) (40, 43-45). We then used MDCKs, a kidney derived cell line, and found that D1DRs and OCT2 can be detected at both the plasma membrane and the Golgi pools (Supplementary Figure 5a-c). These data suggest that distinct OCT2 tissue expression patterns could play a role in regulating spatial D1DR signaling.

Golgi and plasma membrane-localized D1DR both contribute to the cAMP response Our data suggested that the plasma membrane and Golgi pools of D1DR both couple to the Gs protein. In addition to its presence at the plasma membrane, adenylyl cyclase has been reported to localize at the Golgi/perinuclear membranes $(46,47)$. We therefore 
asked whether D1DR/Gs complexes at both the plasma membrane and the Golgi activate Gs-mediated cAMP responses. To address this question, we utilized a rapamycin dimerization system composed of FK506-binding protein (FKBP) and FKBP-rapamycin binding domain of FRAP (FRB), to rapidly induce recruitment of Nb6B9 to specific membrane compartments. This makes it possible to specifically block D1DR/Gs coupling at each distinctly localized pool. We have previously shown that $\beta A R s$ nanobody, Nb80, which binds to the same region as $\mathrm{G}$ protein $(35,48)$, blocks either the plasma membrane or the Golgi- $\beta 1 A R$ mediated CAMP responses when it is recruited locally to these compartments at high concentrations(33). This inhibition is likely due to steric occlusion of the Gas protein. Using HEK293 cells expressing either FKBP at the plasma membrane or the Golgi with FRB fused to Nb6B9 (FRB-Nb6B9), we demonstrated that treatment with rapalog, a rapamycin analog, specifically targets Nb6B9 to either membranes (Figure 3 a-c). Upon stimulation with membrane permeant agonist SKF81297, Nb6B9 targeted to the plasma membrane disrupts plasma membrane-D1DR /G proteins coupling, while Golgi-D1DR is still able to elicit a cAMP response (Figure $3 d$ ). In turn, treatment with rapalog in cells expressing Golgi-targeted FKBP and FRB-Nb6B9 and subsequent stimulation with SKF81297 resulted in only activation of the plasma membrane-D1DR pool (Figure 3e). Importantly, rapalog treatment alone had no effect on the overall cAMP production elicited by Forskolin, a direct activator of adenylyl cyclase (Figure 3f). These data indicate that Golgi-localized D1DR is able to activate cAMP response.

\section{Local activation of PKA at the Golgi depends on selective activation of Golgi- localized D1DR}

A key downstream effector sensed by cAMP is protein kinase A (PKA). PKA is a holoenzyme, consisting of two catalytic and two regulatory subunits (Figure 4a). There are two PKA types (type I and II) that are anchored to distinct subcellular locations through interactions with distinct A kinase anchoring proteins (49). PKA type II has been shown to localize to the perinuclear/Golgi membranes (50). Binding of cAMP to the PKA regulatory subunit induces dissociation and activation of the PKA catalytic subunit (Figure 4a) $(51,52)$. To test whether cAMP generation by Golgi-localized D1DR/Gs complex results in the activation of PKA at the perinuclear/Golgi, we utilized a previously described HEK293T knock-in cell line expressing a split fluorescent protein, labeling native PKA catalytic subunit gene with GFP (PKAcat-GFP)(53). Stimulation of HEK293T PKAcatGFP knock in cell lines expressing D1DR with 10nM SKF81297, a concentration that activates both pools of D1DR (Supplementary Figure 3), resulted in rapid dissociation of PKAcat-GFP from the perinuclear/Golgi membranes (Figure $4 \mathrm{~b}$ top panel). Quantification of these data shows that stimulation with SKF81297 results in sustained activation of PKA at the perinuclear/Golgi regions (Figure 4c, Supplementary Figure 6). We then asked whether PKAcat dissociation is mediated by the activation of D1DR Golgi pool. Given that HEK293T cells do not express OCT2 transporter (Figure 2b) and thus DA cannot be transported to the Golgi membranes, we used DA to specifically activate the plasma membrane pool of D1DR. Importantly, stimulation of HEK293T PKAcat-GFP knock-in cells with 10nM DA, a concentration with similar potency as SKF81297 (Figure 2a), did not cause PKAcat dissociation (Figure $4 \mathrm{~b}$, lower panel, and c). Together, these data indicate that activation of the D1DR at the Golgi, but not the plasma membrane, results in local PKA activation at the perinuclear/Golgi. 


\section{Dopamine uncaging triggers rapid activation of Golgi localized-D1DR and local PKA.}

To further investigate the role of Golgi-localized D1DR in activating PKA locally, we utilized a photo-sensitive caged dopamine that becomes uncaged upon blue light exposure (Figure 5a). Unlike DA, caged-DA is hydrophobic and thus membrane permeant $(54,55)$. To ensure that caged-DA accumulates inside the cell and reaches the Golgilocalized D1DR, we incubated HEK293T PKAcat-GFP knock in cells with $1 \mu \mathrm{M}$ cagedDA for 10 min in a dark incubator. Addition of caged-DA to HEK293T PKAcat-GFP cells did not activate D1DR, as indicated by cytoplasmic localization of Nb6B9-mApple, confirming that DA is inactive in its caged form (Figure $5 \mathrm{~b}$ top panel). Upon stimulation of cells with blue light for 10 seconds, we observed D1DR activation at the Golgi, as detected by rapid Nb6B9-mApple recruitment to the Golgi membranes within seconds after blue light exposure (Figure $5 \mathrm{~b}$ and $\mathrm{c}$, Supplementary movie 6). This was then followed by PKAcat-GFP dissociation from the perinuclear/Golgi regions, as a result of cAMP production and PKA activation (Figure $5 \mathrm{~b}$ and c, Supplementary movie 6). These data further support the notion that Golgi-localized D1DR activates PKA locally.

\section{Discussion}

Our findings demonstrate for the first time that dopaminergic receptors can signal from the Golgi apparatus. We present evidence that dopamine, a hydrophilic catecholamine, can be transported to the Golgi membrane to reach the pre-existing Golgi pool of D1DRs. This transport is facilitated by a low affinity dopamine transporter, OCT2. The Golgi-D1DR comprises a functional signaling pool as it can activate Gas and stimulate cAMP production. Moreover, we have introduced a new approach to selectively interrogate compartmentalized D1DR signaling by inhibiting Gas coupling, using a nanobody-based chemical recruitment system. Additionally, utilizing caged-dopamine, we show that photorelease of dopamine at the Golgi upon rapid UV exposure triggers D1DR-mediated cAMP production and local PKA activation.

The present study also demonstrates the important role of local generation of cAMP by GPCRs in controlling local PKA activation at specific subcellular compartments. It is well established that CAMP mediated signaling specificity depends on the function of compartment specific phosphodiesterases, enzymes that degrade CAMP, limiting the diffusion of this second messenger (56-61). Recent measurements of cAMP mobility suggest a nanometer scale diffusion domain $(29,30)$. The model where cAMP generation by plasma membrane localized receptors propagates in a linear fashion to then control intracellular effectors of cAMP is inconsistent with the nanometer scale of cAMP diffusion range within the cell (62). Thus, our data further provide evidence that PKA activation at a specific compartment requires GPCR activation locally in the vicinity of that compartment.

OCT2 has been previously thought to mainly function as an uptake transporter, helping with the clearance of extracellular DA and terminating DA-mediated signaling pathways (39-42). We found that OCT2 can also facilitate the transport of DA to the Golgi and activate a second phase of signaling by the Golgi-D1DR pools. Published evidence 
suggests that OCT2 is expressed in a number of tissues and cells types that also express D1DRs $(40,43,44)$. Interestingly, however, there are D1DR expressing cell types that do not express OCT2. For example, we found that within the brain, OCT2 is highly expressed in the striatum and moderately in the cortex. In contrast, OCT2 has little to no expression in the hippocampus or substantia nigra (Supplementary figure $5 c$ ) (40). This could potentially explain some of the distinct CAMP/PKA signaling patterns that have been observed in different D1DR expressing neurons. For example, cAMP/PKA responses are longer lasting in striatal neurons compared to pyramidal cortical neurons (55). Therefore, we speculate that the expression pattern of OCT2 may be a determinant of which cell types and tissues exhibit activation of Golgi-pool of D1DRs. The present results expand the concept of GPCR compartmentalized signaling and open additional interesting questions for further studies regarding mechanisms that regulate subcellular GPCR activity by other monoamine transporters such as another dopamine transporter (DAT), 5-HT transporter (SERT), or noradrenaline transporter (NET) $(63,64)$. Establishing GPCR signaling from subcellular compartments is the first step in unraveling the physiological consequences of compartmentalized signaling for each GPCR family member.

\section{Figure legends:}

Figure 1. Conformational biosensor detects activated D1DR at the plasma membrane and the Golgi upon Dopamine stimulation. a. Nb6B9 binds to the receptor exclusively in its active conformation. We fused Nb6B9 to GFP and used it as conformational biosensor for D1DR. b. Confocal images of representative D1DRexpressing HeLa (top panel) and HEK293 cells (lower panel) with Nb6B9-GFP and GalTmRFP expression before and after $10 \mu \mathrm{M}$ dopamine addition. Stimulation with $10 \mu \mathrm{M}$ dopamine results in recruitment of Nb6B9 to active D1DR at plasma membrane and Golgi in HeLa ( $n=15$ cells, Pearson's coefficient $=0.63$, respectively, 5 experiments); $10 \mu \mathrm{M}$ DA treatment only activates plasma membrane localized D1DR in HEK 293 cells $(n=17$ cells, Pearson's coefficient $=0.15,5$ experiments). Right panels show merged images of Nb6BP and the Golgi marker. Arrows indicate active D1DR at plasma membrane; Arrowhead indicates active D1DR at Golgi membrane; Scale bar $=10 \mu \mathrm{m}$ c. Quantification of D1DR activity at Golgi in HeLa and HEK293 cells; Normalized fluorescence intensity of Nb6B9 at Golgi relative to D1DR at Golgi labeled with Snap-tagged-D1DR.

Figure 2. OCT2 facilitated DA transport to the Golgi-Localized D1DR. a. Doseresponse curve of forskolin-normalized D1DR-mediated cAMP response in HEK 293 cells treated with SKF81297 or dopamine; SKF and DA have similar potency and efficacy, thus differences in signaling at Golgi in HEK293 cells are not due to differences in drug potency or efficacy (mean \pm s.e.m., $n=3$ biological replicates). b. Detection of OCT2 expression by Western Blot. HeLa cells express OCT2, while HEK 293 cells do not. c. Representative HEK293 cell expressing Snap-D1DR, Nb6B9-GFP, and OCT2-mApple at indicated times after $10 \mu \mathrm{M}$ addition. Overexpression of OCT2 in HEK293 cells rescues Golgi-localized D1DR activation ( $n=16$ cells, Pearson's coefficient $=0.67,6$ experiments). Arrow indicates active D1DR at plasma membrane; Arrowhead indicates active D1DR at Golgi membrane; Scale bar $=10 \mu \mathrm{m}$. d. Quantification of Nb6B9-GFP recruitment at Golgi in 
HEK293 cells with or without OCT2 overexpression; Normalized fluorescence intensity of Nb6B9-GFP relative to Snap D1DR at Golgi.

Figure 3. Both plasma membrane and Golgi-localized D1DR promote cAMP production. Model of blocking D1DR-Gs coupling at the plasma membrane (a) and Golgi membrane (b) after recruitment of mVenus-FRB-Nb6B9. FKBP was targeted to either the plasma membrane (a) or Golgi membrane (b), and its binding partner FRB-mVenus was fused to Nb6B9. Upon addition of rapalog (rapamycin analog), FKBP and FRB heterodimerize and sequester Nb6B9 to either membranes, disrupting G protein coupling to the receptor and thus blocking signaling from each respective location. $\mathbf{c}$. Representative confocal images of HEK293 cells expressing either plasma membrane (PM) or Golgi targeted FKBP showing mVenus-FRB Nb6B9 localization at indicated times after rapalog addition. Representative cells confirm inducible sequestration of Nb6B9 to either PM or Golgi. Arrow indicates PM; Arrowhead indicates Golgi. d. Forskolinnormalized D1DR-mediated cAMP response with and without rapalog pretreatment $(1 \mu \mathrm{M}$, $15 \mathrm{~min}$ ) and SKF81297 at indicated concentrations in HEK293 expressing PM-FKBP (mean \pm s.e.m., $n=6$ biological replicates, $P$ values of 0.0021 and 0.0015 at $10^{-7}$ and $10^{-}$ ${ }^{6}$, respectively) e. Forskolin-normalized D1DR-mediated cAMP response with and without rapalog pretreatment $(1 \mu \mathrm{M}, 15 \mathrm{~min})$ and SKF81297 at indicated concentrations in HEK293 expressing Golgi-FKBP (mean \pm s.e.m., $n=6$ biological replicates, P values of $<0.0001$ at $10^{-7}$ and $\left.10^{-6}\right)$. f. Effect of $1 \mu \mathrm{M}$ and $10 \mu \mathrm{M}$ rapalog on forskolin-mediated cAMP response ( $n=3$ biological replicates)

Figure 4. Golgi localized PKA is activated by D1DR at the Golgi. a. Model of PKA activation; $c A M P$ binds PKA regulatory subunit $(R)$, rendering PKA catalytic subunit (PKAcat) dissociation. b. Confocal images of representative D1DR-expressing HEK293 cells with endogenous PKA-cat-GFP and GalT-mRFP expression at indicated times after 10nM SKF81927 (top panels; $n=11$ cells, Pearson's coefficient $0.53,3$ biological replicates) or 10nM DA (lower panels, $n=12$ cells, Pearson's coefficient $=0.64,3$ biological replicates). Arrowhead indicates PKAcat at Golgi membrane; Scale bar $=10 \mu \mathrm{m}$. c. Normalized fluorescence intensity of PKAcat relative to Golgi-D1DR after treatment with 10nM DA or 10nM SKF81927.

Figure 5. Rapid activation of Golgi localized-D1DR and PKA by photo-release of dopamine. a. Dopamine is un-caged from (N)-1-(2 Nitrophenyl)ethylcarboxy-3,4dihydroxyphenethylamine (NPEC) upon blue light (UV) exposure. b. Confocal images of representative D1DR-expressing HEK293 cells with endogenous PKA-cat-GFP and Nb6B9-mApple expression, incubated with $1 \mu \mathrm{M}$ NPEC-caged dopamine and at indicated times after blue light exposure ( $n=46$ cells, 4 biological replicates). Arrowhead indicates Nb6B9 recruitment to the Golgi membrane; Scale bar $=10 \mu \mathrm{m}$. c. Normalized fluorescence intensity of Nb6B9-mApple and PKAcat relative to Golgi-D1DR after blue light exposure.

Supplementary Figure 1. Nanobody binding motifs are conserved between $\beta 2 A R$ and D1 dopamine receptor (D1DR). 
Supplementary Figure 2. Conformational biosensor detects activated D1DR at the plasma membrane and the Golgi upon SKF81297 stimulation. Representative FlagD1DR-expressing HEK293 and HeLa cells with Nb6B9-GFP and GalT-mRFP localization

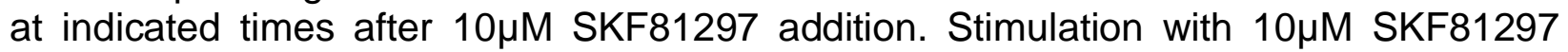
results in recruitment of Nb6B9 to active D1DR at plasma membrane and Golgi in both HEK 293 and HeLa cells. Scale bar $=10 \mu \mathrm{m}$.

Supplementary Figure 3. MiniGas protein biosensor detects active D1DR at the plasma membrane and the Golgi. Representative Snap-D1DR-expressing HeLa cell with miniGs-mVenus and GalT-mRFP localizations at indicated times after 10nM SKF81297 (top panels) and DA (lower panels) addition. Scale bar $=10 \mu \mathrm{m}$.

Supplementary Figure 4. a. Representative HeLa cell expressing Snap-D1DR and Nb6B9-GFP. Cells were incubated with $30 \mu \mathrm{M}$ Dyngo-4a, a dynamin inhibitor that blocks endocytosis, stimulated with $10 \mu \mathrm{M}$ DA at indicated times. Golgi-localized D1DR is activated when endocytosis is blocked, suggesting that activation of the Golgi pool is not dependent on D1DR internalization. b. Representative HeLa cell expressing Snap-D1DR

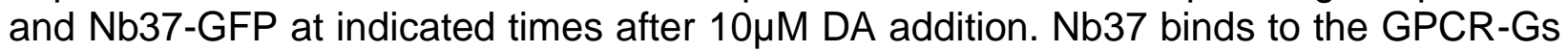
protein complex in the nucleotide free state. Scale bar $=10 \mu \mathrm{m}$. c. Quantification of Nb37GFP and Nb6B9-GFP intensity at Golgi, normalized to Golgi-D1DR. Both nanobodies

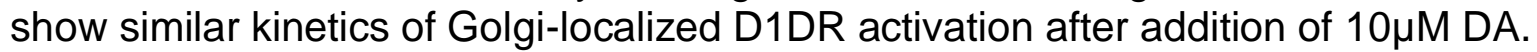

Supplementary Figure 5. a. Endogenous localization of D1DR and b. OCT2 at the plasma membrane and the Golgi membranes. MDCK cells were labeled with D1DR and OCT2 specific antibody and the Golgi antibody (GM130). Arrowheads indicate Golgi localizations. Arrows indicate plasma membrane localization. c. Detection of OCT2 expression in different tissue extracts and brain slices by Western Blot.

Supplementary Figure 6. Kinetics of PKAcat-GFP dissociation from the Golgi membrane upon activation of the D1DR Golgi Pools.

Supplementary Movie 1. Confocal image series of D1DR expressing HeLa cells (magenta), Nb6B9-GFP (cyan) and the Golgi marker (yellow), incubated with $10 \mu \mathrm{M}$ Dopamine.

Supplementary Movie 2. Confocal image series of D1DR expressing HEK293 cells (magenta), Nb6B9-GFP (cyan) and the Golgi marker (yellow), incubated with $10 \mu \mathrm{M}$ Dopamine.

Supplementary Movie 3. Confocal image series of D1DR expressing HeLa cells (magenta), Nb6B9-GFP (cyan) and the Golgi marker (yellow), incubated with $10 \mu \mathrm{M}$ SKF81927.

Supplementary Movie 4. Confocal image series of D1DR expressing HEK293 cells (magenta), Nb6B9-GFP (cyan) and the Golgi marker (yellow), incubated with $10 \mu \mathrm{M}$ SKF81927. 
Supplementary Movie 5. Confocal image series of D1DR expressing HEK293 cells (magenta), Nb6B9-GFP (cyan) and OCT2-mApple (yellow), incubated with $10 \mu \mathrm{M}$ Dopamine.

Supplementary Movie 6. Confocal image series of D1DR expressing (magenta) HEK293 cells with endogenous PKA-cat-GFP (cyan) and Nb6B9-mApple (orange), incubated with $1 \mu \mathrm{M}$ NPEC-caged-Dopamine.

\section{Methods}

\section{Cell Culture, cDNA constructs and transfection}

HeLa and HEK293 cells (purchased from ATCC as authenticated lines CCL-2, CRL-1573 and CRL 1446 respectively) were grown in Dulbecco's minimal essential medium supplemented with $10 \%$ Fetal Bovine Serum (FBS) without antibiotics. Cell cultures were free of mycoplasma contamination. Signal Sequence-Snap-tagged D1DR was created by amplifying D1DR from Flag-D1DR using 5'GCCTGGGCTGGGTCTTGGATCCGATGACGCCATGGACG 5'ATAGGGCCCTCTAGAGCCTCAGGTTGGGTGCTG -3' primers, and inserted into the Snap vector using BamHI and Xbal. pVenus-FRB-Nb6B9 was created by amplifying Nb6B9 and FRB from Nb6B9-GFP (33), and $\mathrm{pC}_{4}-\mathrm{R}_{\mathrm{H}}$ E plasmid (ARIAD Pharmaceuticals), using 5'-TGGTGGACAGGTGCAGCT -3'; GGATCCTCATGAGGAGACGGTGACCTGGGT GCTTCGAATTCAATCCTCTGGCAT -3'; 5'- TGCACCTGTCCACCAGCACTA-3 primers respectively, such that it contained the linker sequence GATAGTGCTGGTAGTGCTGGTGGAC, and inserted into the pVenus-C1 vector using EcoRI and BamH1. FKBP-GalT-mApple was created by amplifying FKBP and GalT from KDELr-FKBP and GalT-mCherry plasmids (a generous gift from Dr.Farese lab), using 5'CATGCTAGCGCCGCCACCATGGGAGTGCAGGTGGAAACCAT-3', 5'GAGCTCGAGACCAGCACTACCAGCACTATCCTCCAGCTTCAGCAGCTCCACG3' and 5'- GCTCAAAGCTTGCCGCCACCGGAAGGCTTCGGGAGCCG-3', 5'ACCGGATCCTTAGGCCCCTCCGGTCCGGAGCTCCCCG-3' primers, respectively and inserted into the pmApple-N1 vector using Nhel, Xhol for FKBP and Hindlll and BamHI for GalT(33). Transfections were performed using Lipofectamine 2000 (Invitrogen) according to the manufacturer's instructions. Snap tagged human D1DR constructs were labelled with Snap-cell 647 SiR (New England Biolabs, S9102S) as described previously (65).

\section{Live-cell confocal imaging}

Live cell imaging was carried out using Nikon spinning disk confocal microscope with a $60 \times, 1.4$ numerical aperture, oil objective and a $\mathrm{CO}_{2}$ and $37^{\circ} \mathrm{C}$ temperature-controlled incubator. A 488, $568 \mathrm{~nm}$ and 640 Voltran was used as light sources for imaging GFP, $\mathrm{mRFP} / \mathrm{mApple}$, and Snap-647 signals, respectively. Cells expressing both Snap-tagged receptor $(2 \mu \mathrm{g})$ and the indicated nanobody-GFP (200ng) were plated onto glass coverslips. Receptors were surface labelled by addition of Snap-Cell $647 \mathrm{SiR}$ (1:1000, 
New England Biolabs) to the media for 20 min, as described previously. Live cell images where endocytosis was inhibited were carried out by incubating the cells in $30 \mu \mathrm{M}$ Dyngo 4a (ab120689) at $37^{\circ} \mathrm{C}$ for 30 minutes before indicated agonist was added. HEK293 PKA-Cat-GFP knock-in cells were a generous gift from the Huang Lab. Indicated agonists (dopamine hydrochloride-Sigma, SKF81297 hydrobromide-Tocris) were added and cells were imaged every $20 \mathrm{~s}$ for 20 min in DMEM without phenol red supplemented with 30 $\mathrm{mM}$ HEPES, pH 7.4. NPEC-caged-dopamine (Tocris) was incubated for $10 \mathrm{~min}$ before cells were stimulated with $3.2 \mu \mathrm{W} / \mathrm{cm}^{2}$ blue light. Time-lapse images were acquired with a CMOS camera (Photometrics) driven by Nikon Imaging Software (NS elements).

\section{Fixed-cell confocal imaging}

Cells were permeabilized with saponin to reduce the cytoplasmic background, as described previously(66). Briefly, MDCK cells were permeabilized with $0.05 \%$ saponin (Sigma) in PEM buffer (80mM K-Pipes, pH 6.8, $5 \mathrm{mM} \mathrm{EGTA,} 1 \mathrm{mM} \mathrm{MgCl}$ ) for 5 min on ice. Cells were then fixed with $3 \%$ paraformaldehyde in PBS for 10 min and then quenched with $50 \mathrm{mM} \mathrm{Nh} 4 \mathrm{Cl}$ in PBS for 15 min. Primary antibodies (D1DR antibody (ab216644) 1:100, GM130 (BD biosciences 610822) (1:1000), and SLC22A2/OCT2 antibody (ab170871) were diluted in PBS supplemented with $0.05 \%$ saponin. Confocal images were taken using Nikon spinning disk confocal microscope with a 60x 1.4 numerical aperture, oil objective.

\section{Image analysis and statistical analysis}

Images were saved as 16-bit TIFF files. Quantitative image analysis was carried out on unprocessed images using ImageJ software (http://rsb.info.nih.gov/ii). For measuring kinetics of Nb6B9-GFP recruitment at the Golgi membrane over time in confocal images and kinetics of PKA-Cat GFP dissociation from the Golgi, analyses were performed on unprocessed TIFF images using custom scripts written in MATLAB. Co-localization analysis at the Golgi was estimated by calculating the Pearson's coefficient between the indicated image channels with the Golgi marker channel, using the co-localization plugin for ImageJ (Coloc2). $P$ values are from two-tailed unpaired Student's $t$-tests calculated using Prism 6.0 software (GraphPad Software).

\section{Luminescence-based cAMP assay}

HEK 293 cells stably expressing D1DR were transfected with a plasmid encoding a cyclicpermuted luciferase reporter construct, (pGloSensor-20F, Promega) and luminescence values were measured, as described previously (17). Briefly, cells were plated in 96-well

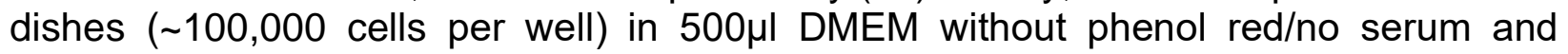
equilibrated to $37^{\circ} \mathrm{C}$ in the SpectraMax plate reader and luminescence was measured every $1.5 \mathrm{~min}$. Software was used to calculate integrated luminescence intensity and background subtraction. In rapamycin heterodimerization experiments, cells were preincubated with $1 \mu \mathrm{M} \mathrm{A} / \mathrm{C}$ heterodimerizer, a rapamycin analog (Takara 635056) for $15 \mathrm{~min}$. $5 \mu \mathrm{M}$ forskolin was used as a reference value in each multi-well plate and for each experimental condition. The average luminescence value (measured across duplicate wells) was normalized to the maximum luminescence value measured in the presence of $5 \mu \mathrm{M}$ forskolin. For rapamycin treated cells, the average luminescence value was 
normalized to the maximum luminescence value measured in the presence of $5 \mu \mathrm{M}$ forskolin and $1 \mu \mathrm{M}$ Rapamycin.

\section{Western blotting}

Cells from HEK293, HEK293T and HeLa were lysed in extraction buffer $(0.2 \%$ Triton X$100,50 \mathrm{mM} \mathrm{NaCl}, 5 \mathrm{mM}$ EDTA, 50mM Tris at pH 7.4 and complete EDTA-free protease inhibitor cocktail (Roche). Extracts were mixed with SDS sample buffer for degradation. The proteins were resolved by SDS-PAGE and transferred to nitrocellulose membrane and blotted for anti-SLC22A2 (ab170871-1:1000) or GAPDH $(1: 10,000)$ antibodies to detect OCT2 and GAPDH expression by horseradish-peroxidase-conjugated rabbit IgG, sheep anti-mouse and rabbit IgG (1:10,000 Amersham Biosciences) and SuperSignal extended duration detection reagent (Pierce).

\section{Data availability}

Our research resources, including methods, cells and protocols are available upon request. All reagents developed, such as FRB and FKBP constructs, as well as detailed methods will be available upon request. The corresponding author adheres to the NIH Grants Policy and Sharing of Unique Research Resources.

\section{Acknowledgments}

We thank K. Silm, A. B. Lobingier, A. Manglik and D. Larsen for assistance, advice and valuable discussion. These studies were supported by the National Institute on General Medicine (GM133521) to R.I.

\section{Author Contributions}

N.P and G.R.R. designed experimental strategy, carried out all of the experiments and analysis. Q.N.M contributed to the cAMP experimental design and analysis. R.I. designed the experimental strategy, contributed to interpreting the results and writing the paper.

\section{Competing financial interests}

The authors declare no competing financial interests.

\section{References}

1. Missale C, Nash SR, Robinson SW, Jaber M, Caron MG. Dopamine receptors: from structure to function. Physiol Rev. 1998;78(1):189-225. Epub 1998/02/11. doi: 10.1152/physrev.1998.78.1.189. PubMed PMID: 9457173.

2. Urs NM, Nicholls PJ, Caron MG. Integrated approaches to understanding antipsychotic drug action at GPCRs. Curr Opin Cell Biol. 2014;27:56-62. Epub 2014/04/01. doi: 10.1016/j.ceb.2013.11.002. PubMed PMID: 24680431; PMCID: PMC5702556.

3. Klein MO, Battagello DS, Cardoso AR, Hauser DN, Bittencourt JC, Correa RG. Dopamine: Functions, Signaling, and Association with Neurological Diseases. Cell Mol Neurobiol. 2019;39(1):31-59. Epub 2018/11/18. doi: 10.1007/s10571-018-0632-3. PubMed PMID: 30446950. 
4. Felder RA, Seikaly MG, Cody P, Eisner GM, Jose PA. Attenuated renal response to dopaminergic drugs in spontaneously hypertensive rats. Hypertension. 1990;15(6 Pt 1):560-9. Epub 1990/06/01. doi: 10.1161/01.hyp.15.6.560. PubMed PMID: 1971811.

5. Kebabian JW. Dopamine-sensitive adenylyl cyclase: a receptor mechanism for dopamine. Adv Biochem Psychopharmacol. 1978;19:131-54. Epub 1978/01/01. PubMed PMID: 29445.

6. Spano PF, Govoni S, Trabucchi M. Studies on the pharmacological properties of dopamine receptors in various areas of the central nervous system. Adv Biochem Psychopharmacol. 1978;19:155-65. Epub 1978/01/01. PubMed PMID: 358777.

7. Beaulieu JM, Espinoza S, Gainetdinov RR. Dopamine receptors - IUPHAR Review 13. $\mathrm{Br} J$ Pharmacol. 2015;172(1):1-23. Epub 2015/02/12. doi: 10.1111/bph.12906. PubMed PMID: 25671228; PMCID: PMC4280963.

8. Honegger KJ, Capuano P, Winter C, Bacic D, Stange G, Wagner CA, Biber J, Murer $\mathrm{H}$, Hernando N. Regulation of sodium-proton exchanger isoform 3 (NHE3) by PKA and exchange protein directly activated by cAMP (EPAC). Proc Natl Acad Sci U S A. 2006;103(3):803-8. Epub 2006/01/13. doi: 10.1073/pnas.0503562103. PubMed PMID: 16407144; PMCID: PMC1334627.

9. Wiederkehr MR, Di Sole F, Collazo R, Quinones H, Fan L, Murer H, Helmle-Kolb $\mathrm{C}$, Moe OW. Characterization of acute inhibition of $\mathrm{Na} / \mathrm{H}$ exchanger NHE-3 by dopamine in opossum kidney cells. Kidney Int. 2001;59(1):197-209. Epub 2001/01/03. doi: 10.1046/j.1523-1755.2001.00480.x. PubMed PMID: 11135072.

10. Ariano MA, Sortwell CE, Ray M, Altemus KL, Sibley DR, Levine MS. Agonistinduced morphologic decrease in cellular D1A dopamine receptor staining. Synapse. 1997;27(4):313-21. Epub 1998/02/12. doi: 10.1002/(SICI)10982396(199712)27:4<313::AID-SYN5>3.0.CO;2-F. PubMed PMID: 9372554.

11. Bloch B, Bernard V, Dumartin B. "In vivo" intraneuronal trafficking of G protein coupled receptors in the striatum: regulation by dopaminergic and cholinergic environment. Biol Cell. 2003;95(7):477-88. Epub 2003/11/05. doi: 10.1016/s02484900(03)00080-7. PubMed PMID: 14597266.

12. Vickery RG, von Zastrow M. Distinct dynamin-dependent and -independent mechanisms target structurally homologous dopamine receptors to different endocytic membranes. J Cell Biol. 1999;144(1):31-43. Epub 1999/01/13. doi: 10.1083/jcb.144.1.31. PubMed PMID: 9885242; PMCID: PMC2148123.

13. Calebiro D, Nikolaev VO, Lohse MJ. Imaging of persistent cAMP signaling by internalized G protein-coupled receptors. J Mol Endocrinol. 2010;45(1):1-8. Epub 2010/04/10. doi: 10.1677/JME-10-0014. PubMed PMID: 20378719.

14. Ferrandon S, Feinstein TN, Castro M, Wang B, Bouley R, Potts JT, Gardella TJ, Vilardaga JP. Sustained cyclic AMP production by parathyroid hormone receptor endocytosis. Nat Chem Biol. 2009;5(10):734-42. Epub 2009/08/25. doi: 10.1038/nchembio.206. PubMed PMID: 19701185; PMCID: PMC3032084.

15. Feinstein TN, Yui N, Webber MJ, Wehbi VL, Stevenson HP, King JD, Jr., Hallows KR, Brown D, Bouley R, Vilardaga JP. Noncanonical control of vasopressin receptor type 2 signaling by retromer and arrestin. J Biol Chem. 2013;288(39):27849-60. Epub 2013/08/13. doi: 10.1074/jbc.M112.445098. PubMed PMID: 23935101; PMCID: PMC3784700. 
16. Kotowski SJ, Hopf FW, Seif T, Bonci A, von Zastrow M. Endocytosis promotes rapid dopaminergic signaling. Neuron. 2011;71(2):278-90. Epub 2011/07/28. doi: 10.1016/j.neuron.2011.05.036. PubMed PMID: 21791287; PMCID: PMC3417347.

17. Irannejad R, Tomshine JC, Tomshine JR, Chevalier M, Mahoney JP, Steyaert J, Rasmussen SG, Sunahara RK, El-Samad H, Huang B, von Zastrow M. Conformational biosensors reveal GPCR signalling from endosomes. Nature. 2013;495(7442):534-8. Epub 2013/03/22. doi: 10.1038/nature12000. PubMed PMID: 23515162; PMCID: PMC3835555.

18. Irannejad R, von Zastrow M. GPCR signaling along the endocytic pathway. Curr Opin Cell Biol. 2014;27:109-16. Epub 2014/04/01. doi: 10.1016/j.ceb.2013.10.003. PubMed PMID: 24680436; PMCID: PMC4968408.

19. Irannejad R, Tsvetanova NG, Lobingier BT, von Zastrow M. Effects of endocytosis on receptor-mediated signaling. Curr Opin Cell Biol. 2015;35:137-43. Epub 2015/06/10. doi: 10.1016/j.ceb.2015.05.005. PubMed PMID: 26057614; PMCID: PMC4529812.

20. Thomsen ARB, Jensen DD, Hicks GA, Bunnett NW. Therapeutic Targeting of Endosomal G-Protein-Coupled Receptors. Trends Pharmacol Sci. 2018;39(10):879-91. Epub 2018/09/06. doi: 10.1016/j.tips.2018.08.003. PubMed PMID: 30180973; PMCID: PMC6508874.

21. Calebiro D, Koszegi Z. The subcellular dynamics of GPCR signaling. Mol Cell Endocrinol. 2019;483:24-30. Epub 2019/01/06. doi: 10.1016/j.mce.2018.12.020. PubMed PMID: 30610913.

22. Lobingier BT, von Zastrow M. When trafficking and signaling mix: How subcellular location shapes $\mathrm{G}$ protein-coupled receptor activation of heterotrimeric $\mathrm{G}$ proteins. Traffic. 2019;20(2):130-6. Epub 2018/12/24. doi: 10.1111/tra.12634. PubMed PMID: 30578610; PMCID: PMC6387827.

23. Stoeber M, Jullie D, Lobingier BT, Laeremans T, Steyaert J, Schiller PW, Manglik A, von Zastrow M. A Genetically Encoded Biosensor Reveals Location Bias of Opioid Drug Action. Neuron. 2018;98(5):963-76 e5. Epub 2018/05/15. doi: 10.1016/j.neuron.2018.04.021. PubMed PMID: 29754753; PMCID: PMC6481295.

24. Tsvetanova NG, von Zastrow M. Spatial encoding of cyclic AMP signaling specificity by GPCR endocytosis. Nat Chem Biol. 2014;10(12):1061-5. Epub 2014/11/05. doi: 10.1038/nchembio.1665. PubMed PMID: 25362359; PMCID: PMC4232470.

25. Bowman SL, Shiwarski DJ, Puthenveedu MA. Distinct G protein-coupled receptor recycling pathways allow spatial control of downstream G protein signaling. J Cell Biol. 2016;214(7):797-806. Epub 2016/09/21. doi: 10.1083/jcb.201512068. PubMed PMID: 27646272 ; PMCID: PMC5037407.

26. Jensen DD, Lieu T, Halls ML, Veldhuis NA, Imlach WL, Mai QN, Poole DP, Quach T, Aurelio L, Conner J, Herenbrink CK, Barlow N, Simpson JS, Scanlon MJ, Graham B, McCluskey A, Robinson PJ, Escriou V, Nassini R, Materazzi S, Geppetti P, Hicks GA, Christie MJ, Porter CJH, Canals M, Bunnett NW. Neurokinin 1 receptor signaling in endosomes mediates sustained nociception and is a viable therapeutic target for prolonged pain relief. Sci Transl Med. 2017;9(392). Epub 2017/06/02. doi: 10.1126/scitransImed.aal3447. PubMed PMID: 28566424; PMCID: PMC6034632.

27. Godbole A, Lyga S, Lohse MJ, Calebiro D. Internalized TSH receptors en route to the TGN induce local Gs-protein signaling and gene transcription. Nat Commun. 
2017;8(1):443. Epub 2017/09/07. doi: 10.1038/s41467-017-00357-2. PubMed PMID: 28874659; PMCID: PMC5585343.

28. Jean-Alphonse F, Bowersox S, Chen S, Beard G, Puthenveedu MA, Hanyaloglu AC. Spatially restricted $G$ protein-coupled receptor activity via divergent endocytic compartments. J Biol Chem. 2014;289(7):3960-77. Epub 2014/01/01. doi: 10.1074/jbc.M113.526350. PubMed PMID: 24375413; PMCID: PMC3924264.

29. Bock A, Annibale P, Konrad C, Hannawacker A, Anton SE, Maiellaro I, Zabel U, Sivaramakrishnan S, Falcke M, Lohse MJ. Optical Mapping of cAMP Signaling at the Nanometer Scale. Cell. 2020;182(6):1519-30 e17. Epub 2020/08/28. doi: 10.1016/j.cell.2020.07.035. PubMed PMID: 32846156.

30. Saucerman JJ, Greenwald EC, Polanowska-Grabowska R. Mechanisms of cyclic AMP compartmentation revealed by computational models. J Gen Physiol. 2014;143(1):39-48. Epub 2014/01/01. doi: 10.1085/jgp.201311044. PubMed PMID: 24378906; PMCID: PMC3874575.

31. Richards M, Lomas O, Jalink K, Ford KL, Vaughan-Jones RD, Lefkimmiatis K, Swietach P. Intracellular tortuosity underlies slow cAMP diffusion in adult ventricular myocytes. Cardiovasc Res. 2016;110(3):395-407. Epub 2016/04/20. doi: 10.1093/cvr/cvw080. PubMed PMID: 27089919; PMCID: PMC4872880.

32. Agarwal SR, Clancy CE, Harvey RD. Mechanisms Restricting Diffusion of Intracellular cAMP. Sci Rep. 2016;6:19577. Epub 2016/01/23. doi: 10.1038/srep19577. PubMed PMID: 26795432; PMCID: PMC4726171.

33. Irannejad R, Pessino V, Mika D, Huang B, Wedegaertner PB, Conti M, von Zastrow M. Functional selectivity of GPCR-directed drug action through location bias. Nat Chem Biol. 2017;13(7):799-806. Epub 2017/05/30. doi: 10.1038/nchembio.2389. PubMed PMID: 28553949; PMCID: PMC5733145.

34. Nash CA, Wei W, Irannejad R, Smrcka AV. Golgi localized beta1-adrenergic receptors stimulate Golgi PI4P hydrolysis by PLCepsilon to regulate cardiac hypertrophy. Elife. 2019;8. Epub 2019/08/23. doi: 10.7554/eLife.48167. PubMed PMID: 31433293; PMCID: PMC6726460.

35. Rasmussen SG, Choi HJ, Fung JJ, Pardon E, Casarosa P, Chae PS, Devree BT, Rosenbaum DM, Thian FS, Kobilka TS, Schnapp A, Konetzki I, Sunahara RK, Gellman $\mathrm{SH}$, Pautsch A, Steyaert J, Weis WI, Kobilka BK. Structure of a nanobody-stabilized active state of the beta(2) adrenoceptor. Nature. 2011;469(7329):175-80. Epub 2011/01/14. doi: 10.1038/nature09648. PubMed PMID: 21228869; PMCID: PMC3058308.

36. Ring AM, Manglik A, Kruse AC, Enos MD, Weis WI, Garcia KC, Kobilka BK. Adrenaline-activated structure of beta2-adrenoceptor stabilized by an engineered nanobody. Nature. 2013;502(7472):575-9. Epub 2013/09/24. doi: 10.1038/nature12572. PubMed PMID: 24056936; PMCID: PMC3822040.

37. Wan Q, Okashah N, Inoue A, Nehme R, Carpenter B, Tate CG, Lambert NA. Mini $G$ protein probes for active $G$ protein-coupled receptors (GPCRs) in live cells. J Biol Chem. 2018;293(19):7466-73. Epub 2018/03/11. doi: 10.1074/jbc.RA118.001975. PubMed PMID: 29523687; PMCID: PMC5949987.

38. Nies AT, Koepsell H, Damme K, Schwab M. Organic cation transporters (OCTs, MATEs), in vitro and in vivo evidence for the importance in drug therapy. Handb Exp 
Pharmacol. 2011(201):105-67. Epub 2010/11/26. doi: 10.1007/978-3-642-14541-4_3. PubMed PMID: 21103969.

39. Taubert D, Grimberg G, Stenzel W, Schomig E. Identification of the endogenous key substrates of the human organic cation transporter OCT2 and their implication in function of dopaminergic neurons. PLoS One. 2007;2(4):e385. Epub 2007/04/27. doi: 10.1371/journal.pone.0000385. PubMed PMID: 17460754; PMCID: PMC1851987.

40. Busch AE, Karbach U, Miska D, Gorboulev V, Akhoundova A, Volk C, Arndt P, Ulzheimer JC, Sonders MS, Baumann C, Waldegger S, Lang F, Koepsell H. Human neurons express the polyspecific cation transporter hOCT2, which translocates monoamine neurotransmitters, amantadine, and memantine. Mol Pharmacol. 1998;54(2):342-52. Epub 1998/08/04. doi: 10.1124/mol.54.2.342. PubMed PMID: 9687576.

41. Bednarczyk D, Ekins S, Wikel JH, Wright SH. Influence of molecular structure on substrate binding to the human organic cation transporter, hOCT1. Mol Pharmacol. 2003;63(3):489-98. Epub 2003/02/28. doi: 10.1124/mol.63.3.489. PubMed PMID: 12606755.

42. Amphoux A, Vialou V, Drescher E, Bruss M, Mannoury La Cour C, Rochat C, Millan MJ, Giros B, Bonisch H, Gautron S. Differential pharmacological in vitro properties of organic cation transporters and regional distribution in rat brain. Neuropharmacology. 2006;50(8):941-52. Epub 2006/04/04. doi: 10.1016/j.neuropharm.2006.01.005. PubMed PMID: 16581093.

43. Double KL, Crocker AD. Dopamine receptors in the substantia nigra are involved in the regulation of muscle tone. Proc Natl Acad Sci U S A. 1995;92(5):1669-73. Epub 1995/02/28. doi: 10.1073/pnas.92.5.1669. PubMed PMID: 7878037; PMCID: PMC42581. 44. Arnsten AF, Cai JX, Steere JC, Goldman-Rakic PS. Dopamine D2 receptor mechanisms contribute to age-related cognitive decline: the effects of quinpirole on memory and motor performance in monkeys. J Neurosci. 1995;15(5 Pt 1):3429-39. Epub 1995/05/01. PubMed PMID: 7751922; PMCID: PMC6578230.

45. Alburges ME, Hunt ME, McQuade RD, Wamsley JK. D1-receptor antagonists: comparison of [3H]SCH39166 to [3H]SCH23390. J Chem Neuroanat. 1992;5(5):357-66. Epub 1992/09/01. doi: 10.1016/0891-0618(92)90051-q. PubMed PMID: 1358117.

46. Cancino J, Capalbo A, Di Campli A, Giannotta M, Rizzo R, Jung JE, Di Martino R, Persico M, Heinklein P, Sallese M, Luini A. Control systems of membrane transport at the interface between the endoplasmic reticulum and the Golgi. Dev Cell. 2014;30(3):280-94. Epub 2014/08/15. doi: 10.1016/j.devcel.2014.06.018. PubMed PMID: 25117681.

47. Boivin B, Lavoie C, Vaniotis G, Baragli A, Villeneuve LR, Ethier N, Trieu P, Allen $B G$, Hebert TE. Functional beta-adrenergic receptor signalling on nuclear membranes in adult rat and mouse ventricular cardiomyocytes. Cardiovasc Res. 2006;71(1):69-78. Epub 2006/04/25. doi: 10.1016/j.cardiores.2006.03.015. PubMed PMID: 16631628.

48. Chung KY, Rasmussen SG, Liu T, Li S, DeVree BT, Chae PS, Calinski D, Kobilka BK, Woods VL, Jr., Sunahara RK. Conformational changes in the G protein Gs induced by the beta2 adrenergic receptor. Nature. 2011;477(7366):611-5. Epub 2011/10/01. doi: 10.1038/nature10488. PubMed PMID: 21956331; PMCID: PMC3448949.

49. Soberg K, Skalhegg BS. The Molecular Basis for Specificity at the Level of the Protein Kinase a Catalytic Subunit. Front Endocrinol (Lausanne). 2018;9:538. Epub 
2018/09/28. doi: 10.3389/fendo.2018.00538. PubMed PMID: 30258407; PMCID: PMC6143667.

50. Nigg EA, Schafer G, Hilz H, Eppenberger HM. Cyclic-AMP-dependent protein kinase type II is associated with the Golgi complex and with centrosomes. Cell. 1985;41(3):1039-51. Epub 1985/07/01. doi: 10.1016/s0092-8674(85)80084-2. PubMed PMID: 2988780.

51. Tillo SE, Xiong WH, Takahashi M, Miao S, Andrade AL, Fortin DA, Yang G, Qin M, Smoody BF, Stork PJS, Zhong H. Liberated PKA Catalytic Subunits Associate with the Membrane via Myristoylation to Preferentially Phosphorylate Membrane Substrates. Cell Rep. 2017;19(3):617-29. Epub 2017/04/20. doi: 10.1016/j.celrep.2017.03.070. PubMed PMID: 28423323; PMCID: PMC5481286.

52. Walker-Gray R, Stengel F, Gold MG. Mechanisms for restraining cAMP-dependent protein kinase revealed by subunit quantitation and cross-linking approaches. Proc Natl Acad Sci U S A. 2017;114(39):10414-9. Epub 2017/09/13. doi: 10.1073/pnas.1701782114. PubMed PMID: 28893983; PMCID: PMC5625894.

53. Feng S, Sekine S, Pessino V, Li H, Leonetti MD, Huang B. Improved split fluorescent proteins for endogenous protein labeling. Nat Commun. 2017;8(1):370. Epub 2017/08/31. doi: 10.1038/s41467-017-00494-8. PubMed PMID: 28851864; PMCID: PMC5575300.

54. Yapo C, Nair AG, Clement L, Castro LR, Hellgren Kotaleski J, Vincent P. Detection of phasic dopamine by D1 and D2 striatal medium spiny neurons. J Physiol. 2017;595(24):7451-75. Epub 2017/08/07. doi: 10.1113/JP274475. PubMed PMID: 28782235; PMCID: PMC5730852.

55. Castro LR, Brito M, Guiot E, Polito M, Korn CW, Herve D, Girault JA, PaupardinTritsch D, Vincent P. Striatal neurones have a specific ability to respond to phasic dopamine release. J Physiol. 2013;591(13):3197-214. Epub 2013/04/05. doi: 10.1113/jphysiol.2013.252197. PubMed PMID: 23551948; PMCID: PMC3717223.

56. Buxton IL, Brunton LL. Compartments of cyclic AMP and protein kinase in mammalian cardiomyocytes. J Biol Chem. 1983;258(17):10233-9. Epub 1983/09/10. PubMed PMID: 6309796.

57. Agarwal SR, MacDougall DA, Tyser R, Pugh SD, Calaghan SC, Harvey RD. Effects of cholesterol depletion on compartmentalized cAMP responses in adult cardiac myocytes. J Mol Cell Cardiol. 2011;50(3):500-9. Epub 2010/12/01. doi: 10.1016/j.yjmcc.2010.11.015. PubMed PMID: 21115018; PMCID: PMC3049871.

58. Warrier S, Ramamurthy G, Eckert RL, Nikolaev VO, Lohse MJ, Harvey RD. cAMP microdomains and L-type $\mathrm{Ca2}+$ channel regulation in guinea-pig ventricular myocytes. $J$ Physiol. 2007;580(Pt.3):765-76. Epub 2007/02/10. doi: 10.1113/jphysiol.2006.124891. PubMed PMID: 17289786; PMCID: PMC2075464.

59. Steinberg SF, Brunton LL. Compartmentation of G protein-coupled signaling pathways in cardiac myocytes. Annu Rev Pharmacol Toxicol. 2001;41:751-73. Epub 2001/03/27. doi: 10.1146/annurev.pharmtox.41.1.751. PubMed PMID: 11264475.

60. Musheshe N, Schmidt M, Zaccolo M. cAMP: From Long-Range Second Messenger to Nanodomain Signalling. Trends Pharmacol Sci. 2018;39(2):209-22. Epub 2018/01/01. doi: 10.1016/j.tips.2017.11.006. PubMed PMID: 29289379. 
61. Gold MG, Gonen T, Scott JD. Local CAMP signaling in disease at a glance. J Cell Sci. 2013;126(Pt 20):4537-43. Epub 2013/10/15. doi: 10.1242/jcs.133751. PubMed PMID: 24124191; PMCID: PMC3795333.

62. Zaccolo M, Zerio A, Lobo MJ. Subcellular Organization of the cAMP Signaling Pathway. Pharmacol Rev. 2021;73(1):278-309. Epub 2020/12/19. doi: 10.1124/pharmrev.120.000086. PubMed PMID: 33334857 ; PMCID: PMC7770493 this article.

63. Lin Z, Canales JJ, Bjorgvinsson T, Thomsen M, Qu H, Liu QR, Torres GE, Caine SB. Monoamine transporters: vulnerable and vital doorkeepers. Prog Mol Biol Transl Sci. 2011;98:1-46. Epub 2011/01/05. doi: 10.1016/B978-0-12-385506-0.00001-6. PubMed PMID: 21199769; PMCID: PMC3321928.

64. Torres GE, Gainetdinov RR, Caron MG. Plasma membrane monoamine transporters: structure, regulation and function. Nat Rev Neurosci. 2003;4(1):13-25. Epub 2003/01/04. doi: 10.1038/nrn1008. PubMed PMID: 12511858.

65. Lukinavicius G, Umezawa K, Olivier N, Honigmann A, Yang G, Plass T, Mueller V, Reymond L, Correa IR, Jr., Luo ZG, Schultz C, Lemke EA, Heppenstall P, Eggeling C, Manley S, Johnsson K. A near-infrared fluorophore for live-cell super-resolution microscopy of cellular proteins. Nat Chem. 2013;5(2):132-9. Epub 2013/01/25. doi: 10.1038/nchem.1546. PubMed PMID: 23344448.

66. Lobert VH, Stenmark $\mathrm{H}$. The ESCRT machinery mediates polarization of fibroblasts through regulation of myosin light chain. J Cell Sci. 2012;125(Pt 1):29-36. Epub 2012/01/24. doi: 10.1242/jcs.088310. PubMed PMID: 22266905. 

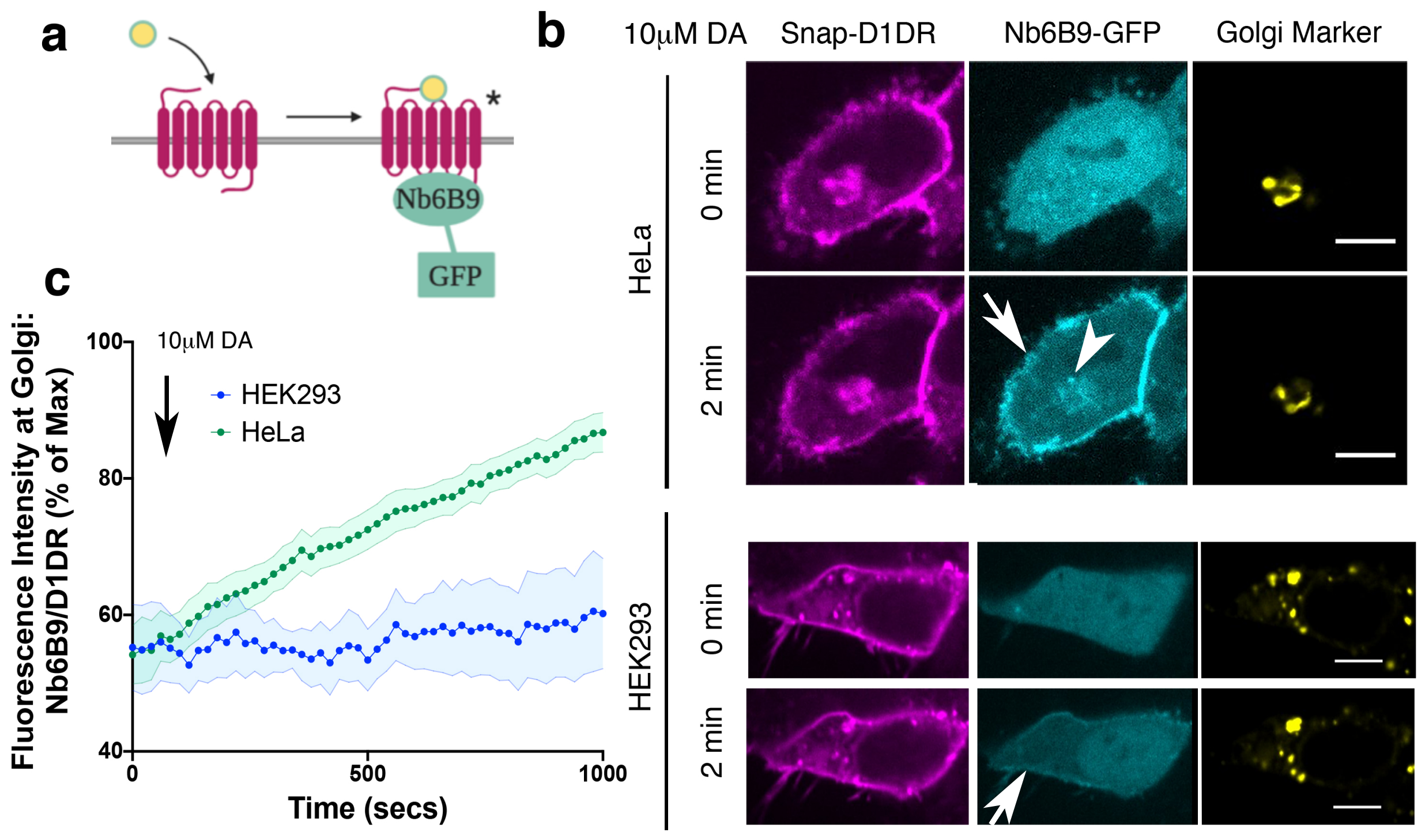

Figure 1 


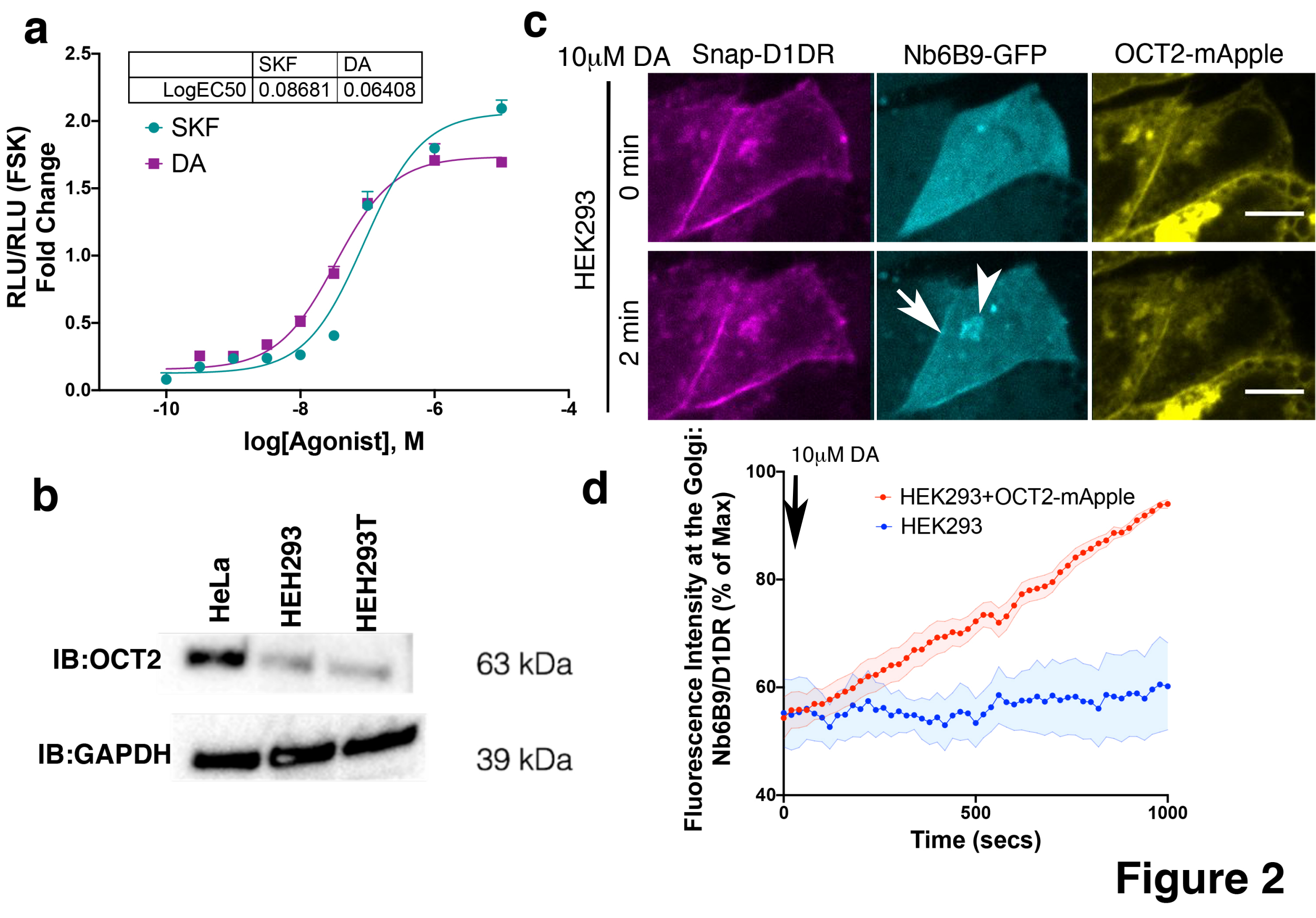


a
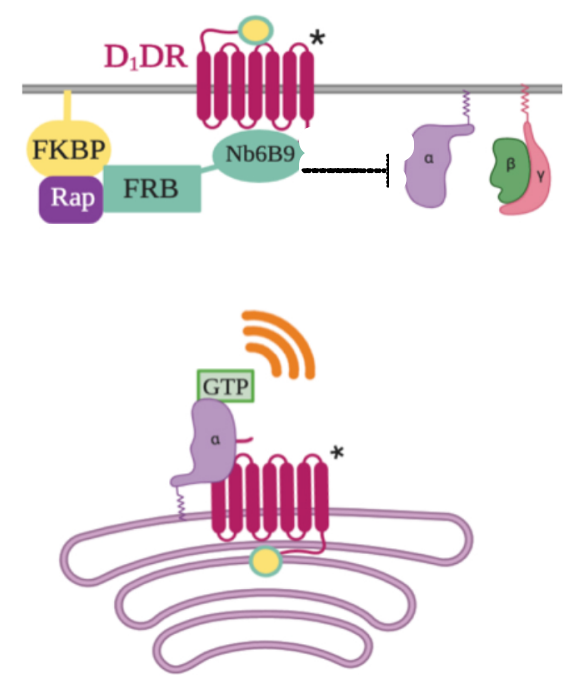

d

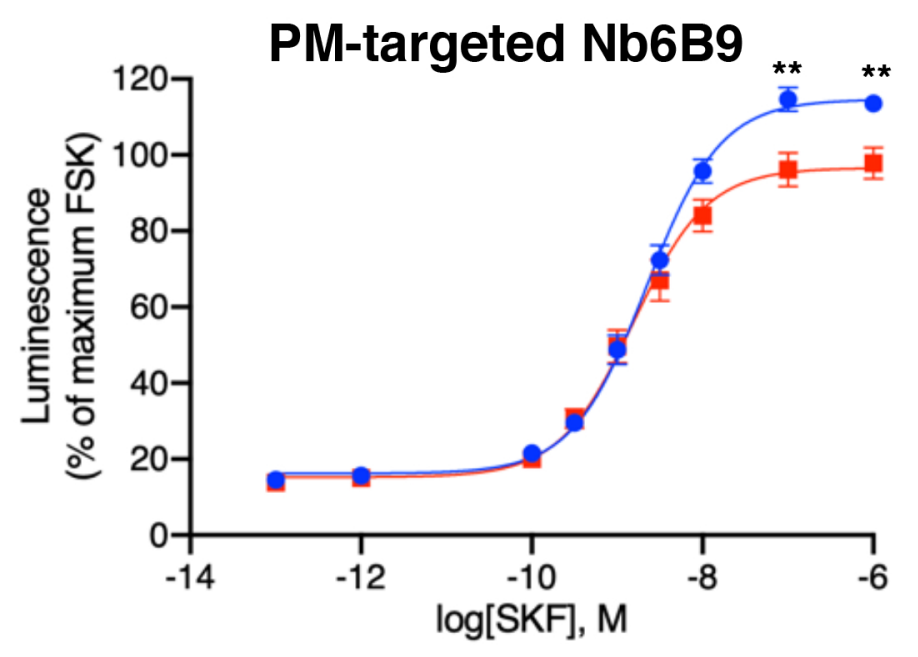

$\rightarrow$ SKF b
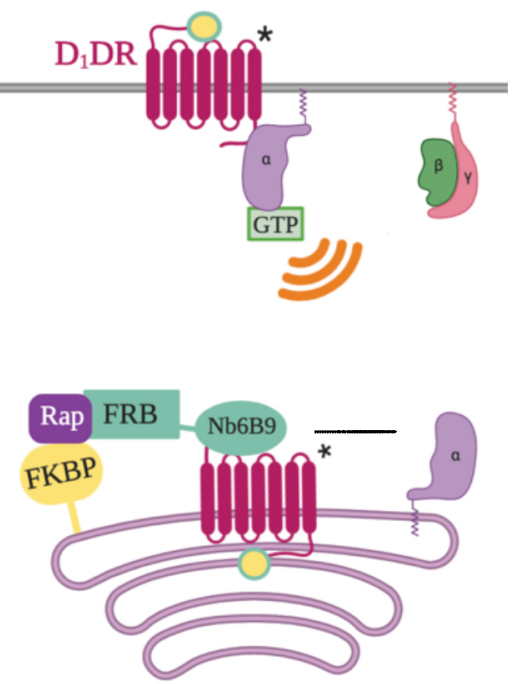

e c mVenus-FRB $1 \mu \mathrm{M}$ Rap Nb6B9 $1 \mu \mathrm{M}$ Rap
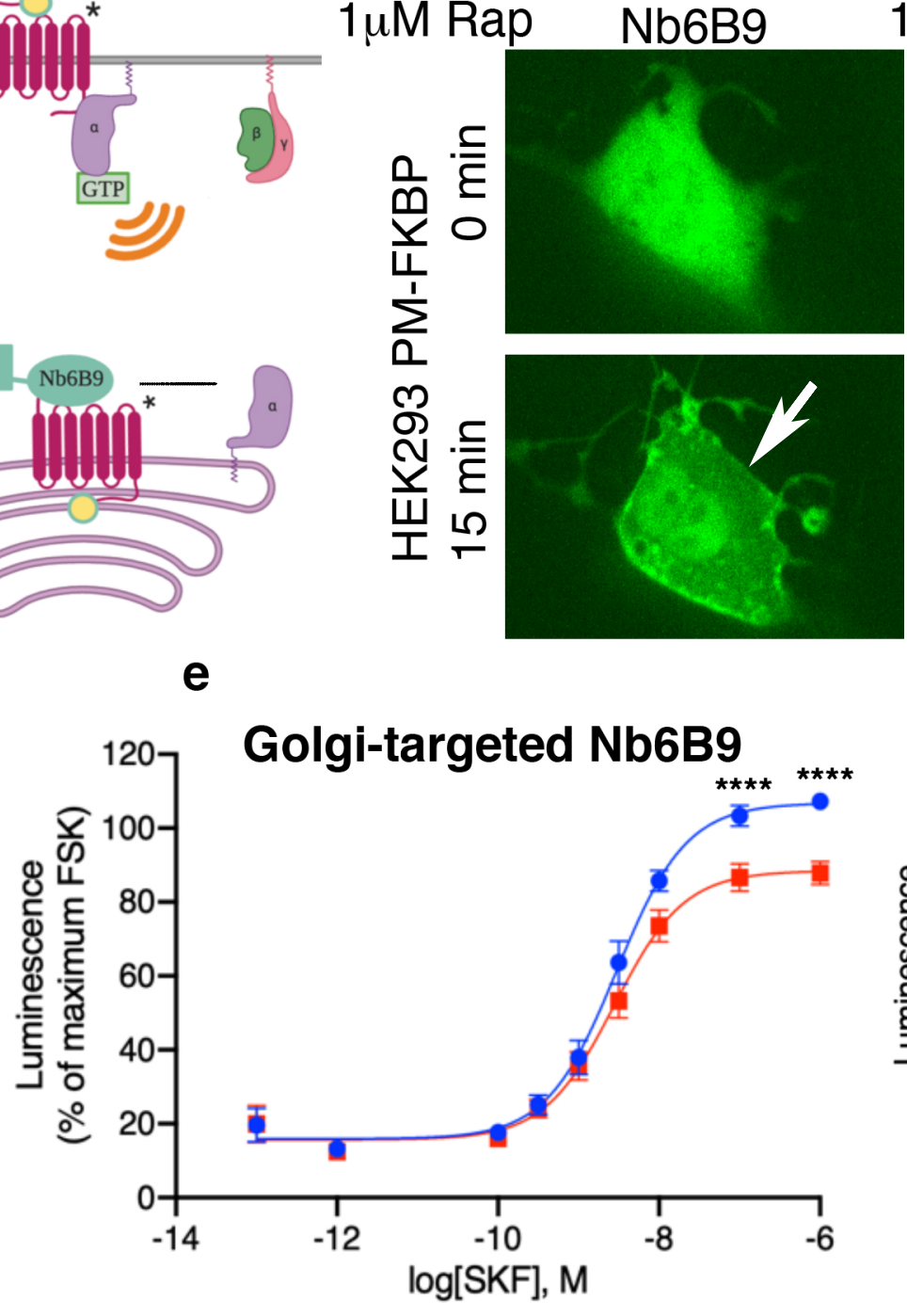

$\rightarrow$ SKF

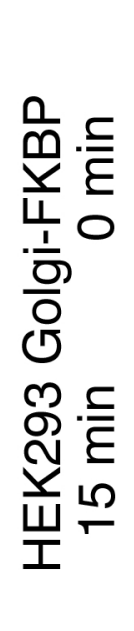

mVenus-FRB

Nb6B9
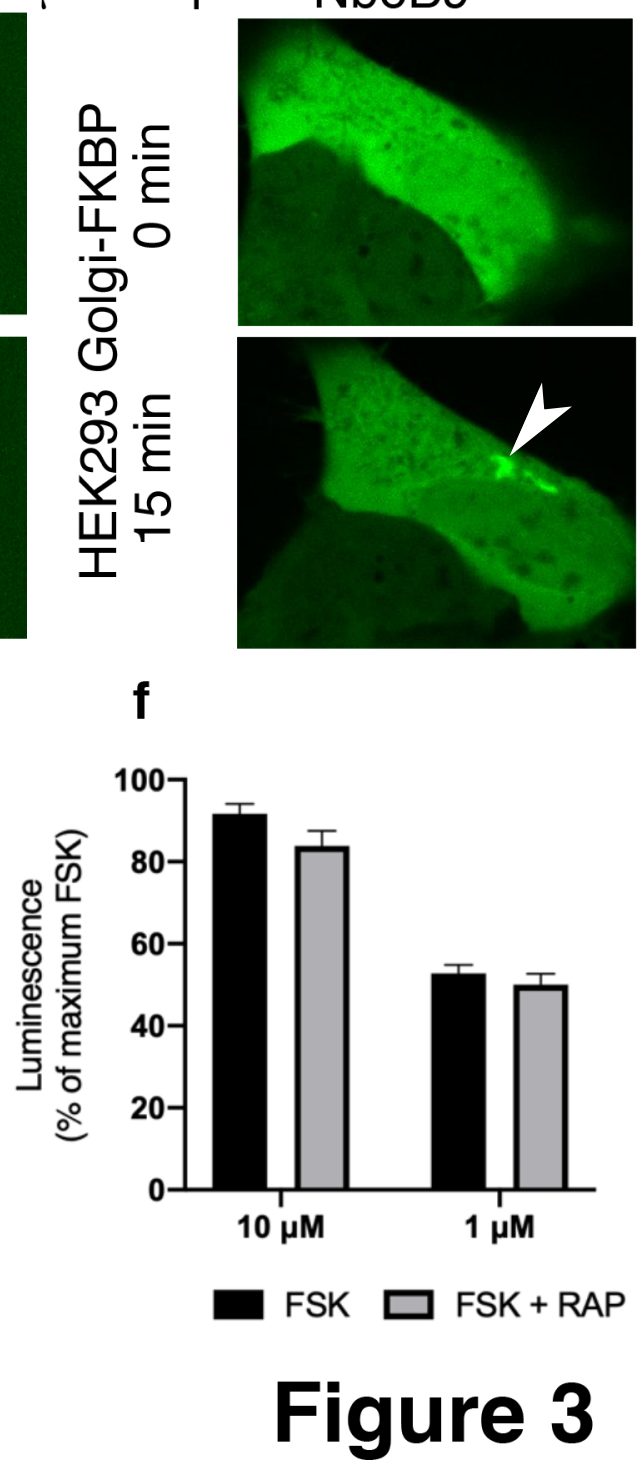
a

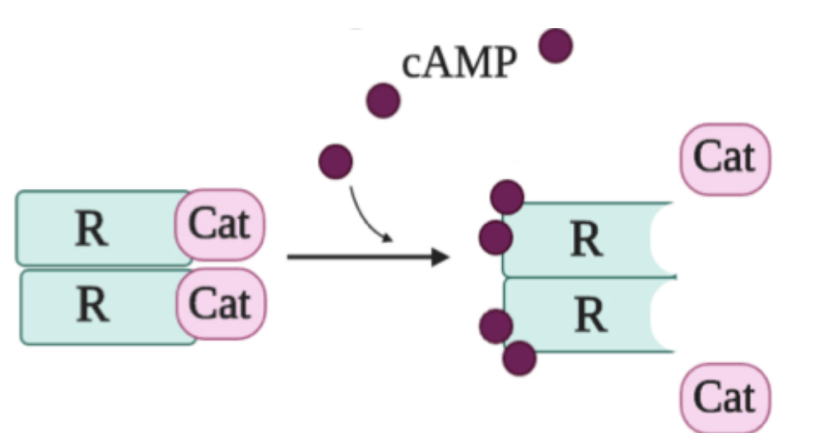

PKA Holoenzyme

C

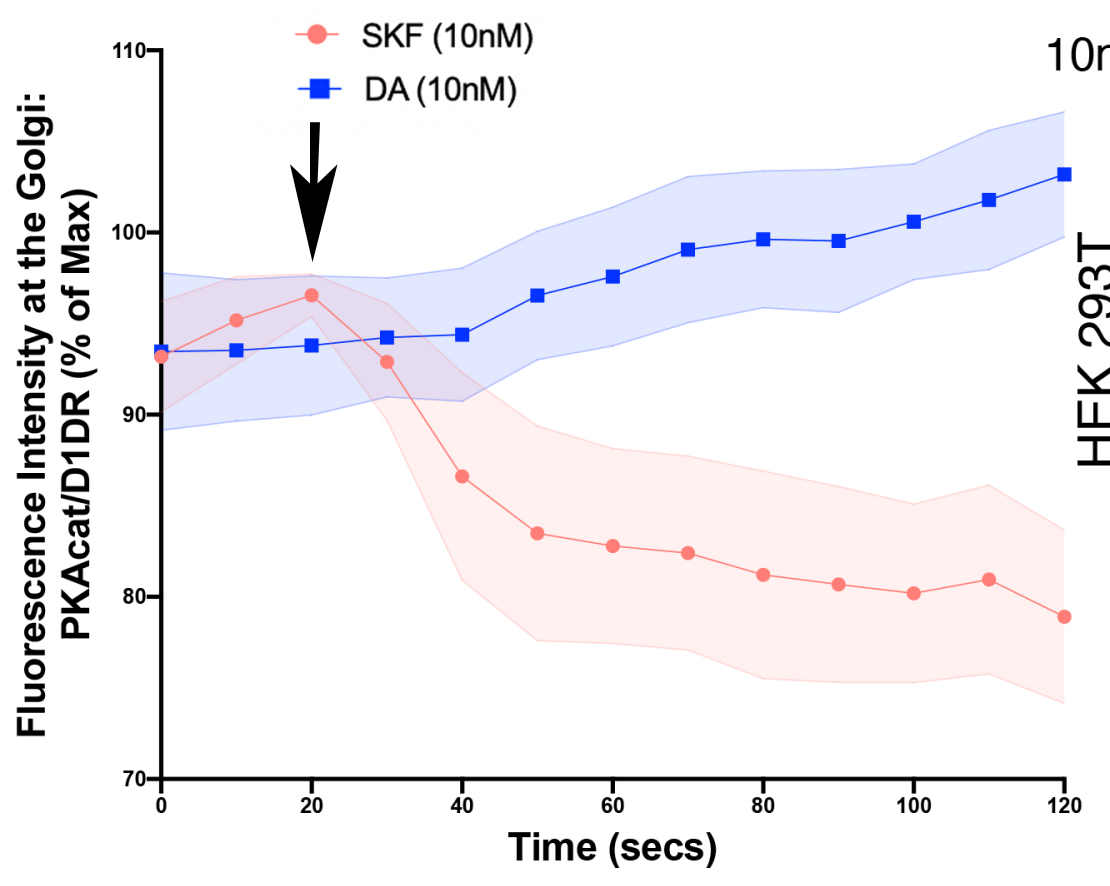

b

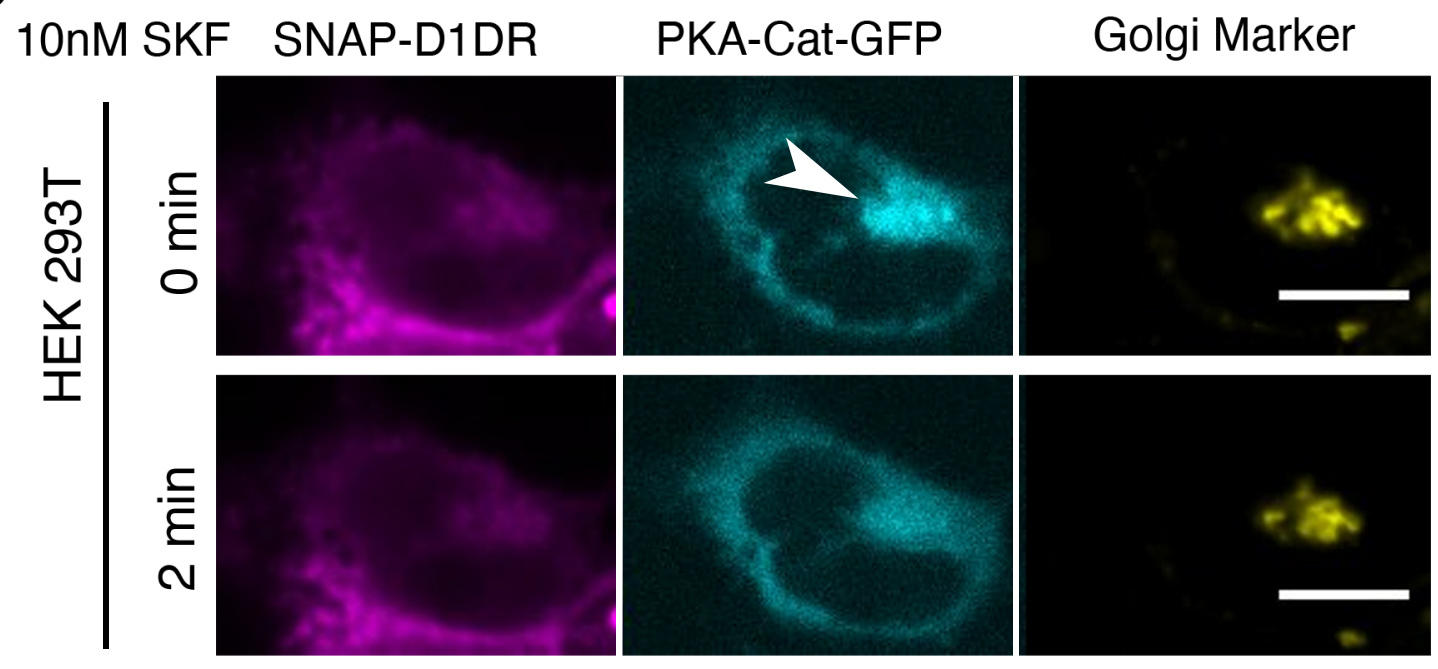

OnM DA

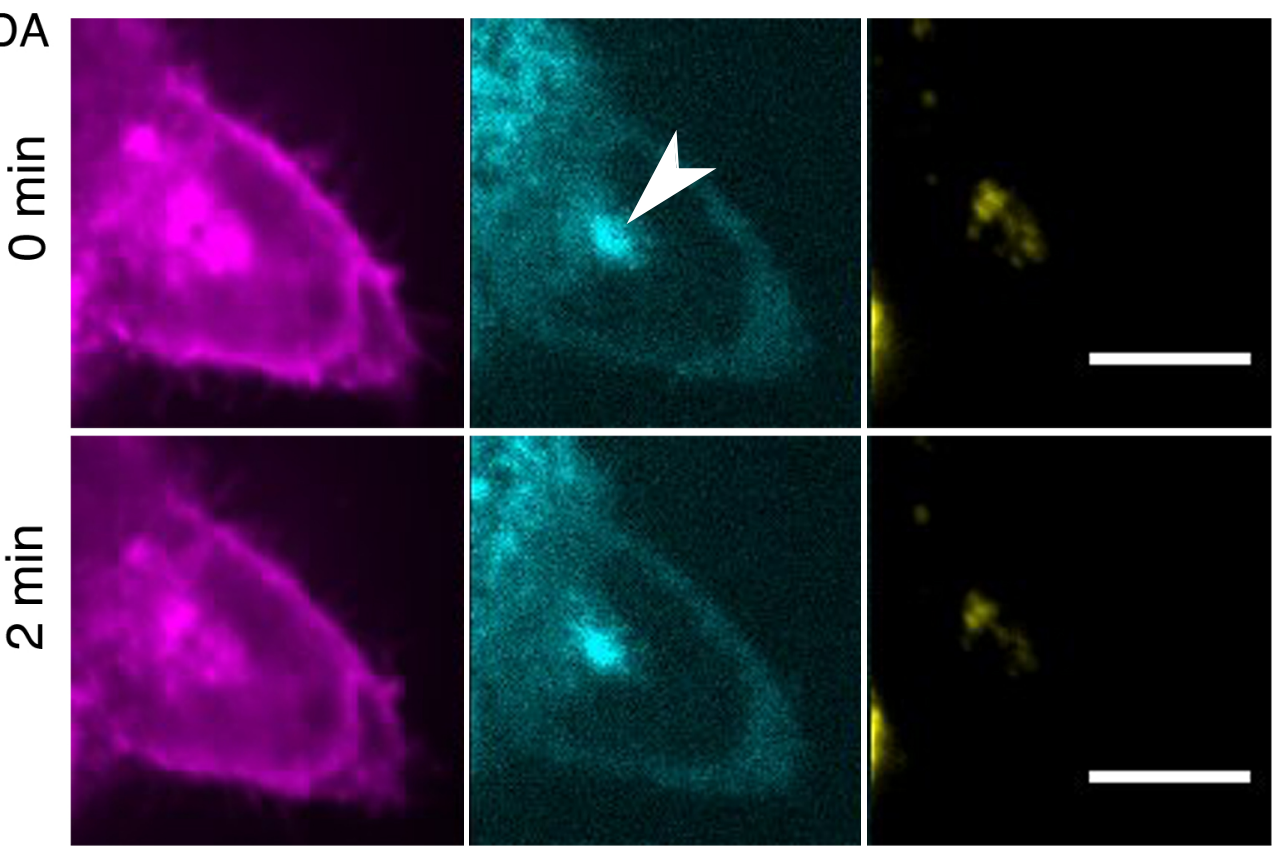

Figure 4 
a

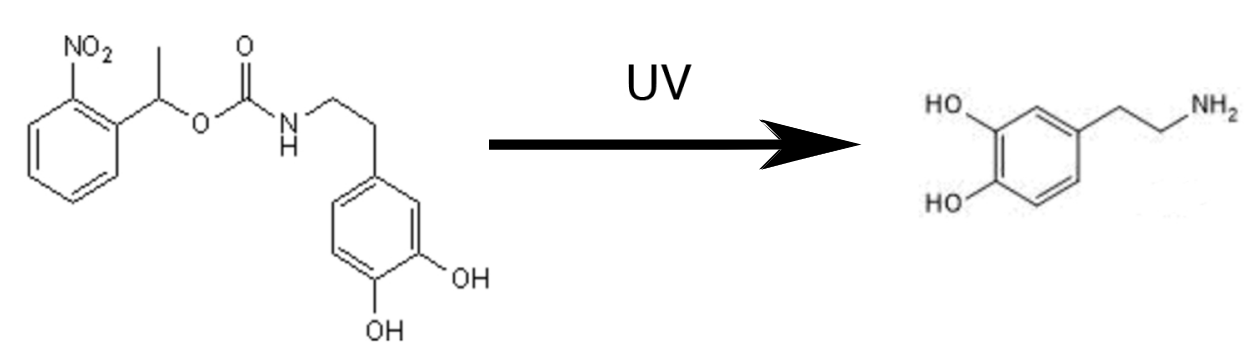

b

b UV

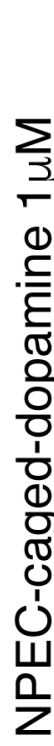

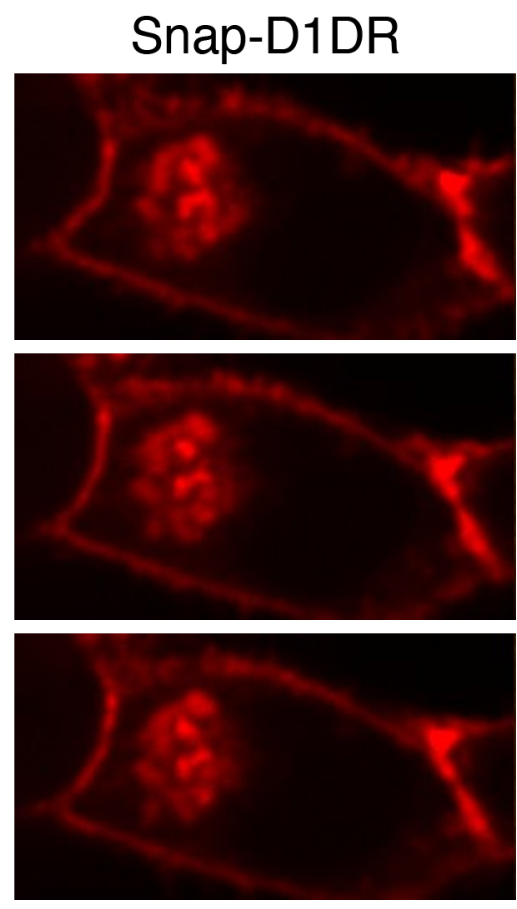

Nb6B9-mApple

PKACA-GFP

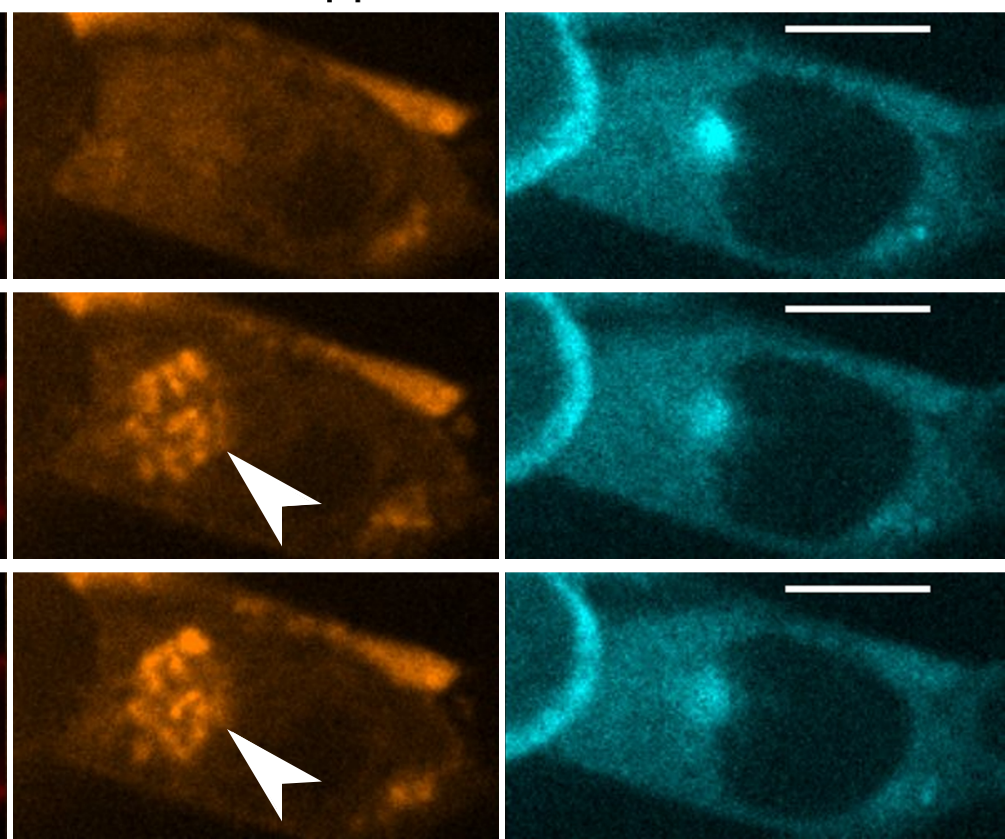

C

D1DR activation at the Golgi

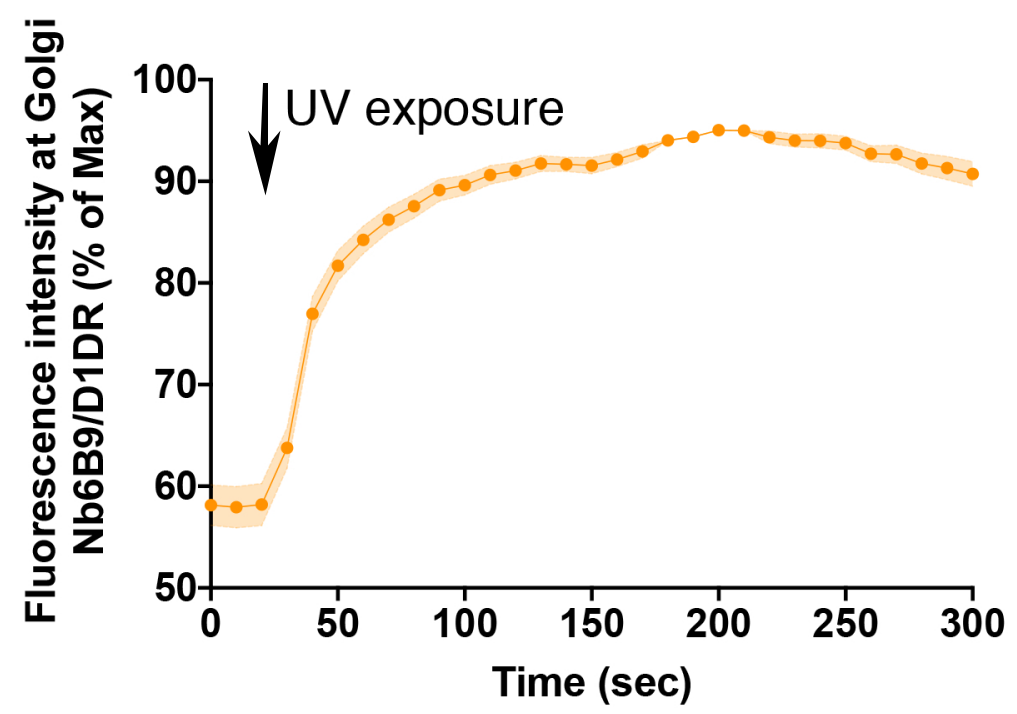

PKAcat activation

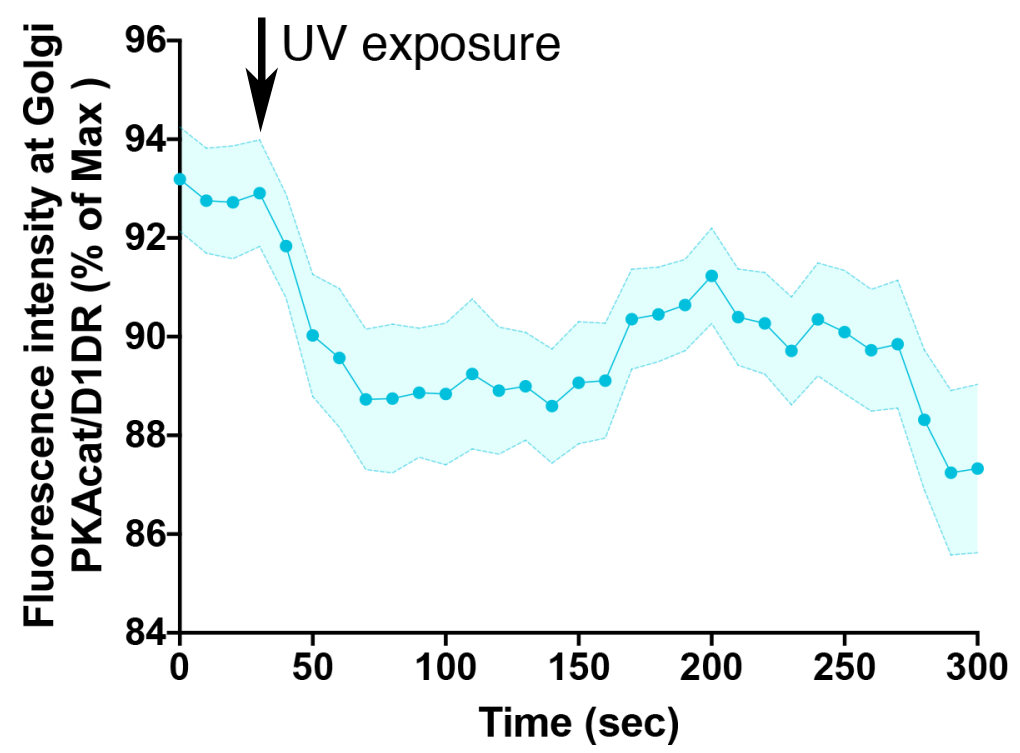

Figure 5 


$\begin{array}{lcll}\text { D1DR } & 17 & \text { ERDFSVRILTACFLSLLILSTLLGNTLVCAAVIRFRHLRSKVTNFFVISLAVSDLLVAVL } & 76 \\ \beta 2 A R & 27 & \text { ERDEVWVVGMGIVMSLIVLAIVFGNVLVITAIAKFERLQT-VTNYFITSLACADLVMGLA } & 85 \\ \text { D1DR } & 77 & \text { VMPWKAVAEIAGFWPFGSF-CNIWVAFDIMCSTASILNLCVISVDRYWAISSPFRYERKM } & 135 \\ \beta 2 A R & 86 & \text { VVPFGAAHILMKMWTFGNFWCEFWTSIDVLCVTASIETLCVIAVDRYFAITSPFKYQSLL } & 145 \\ \text { D1DR } & 136 & \text { TPKAAFILISVAWTLSVLISFIPVQLSWHKAKPTSPSDGNATSLAETIDNCDSSLSRTYA } & 195 \\ \beta 2 A R & 146 & \text { TKNKARVIILMVWIVSGLTSFLPIQMHWYRATHQEAINCYANETC-----CDFFTNQAYA } & 200 \\ \text { D1DR } & 196 & \text { ISSSVISFYIPVAIMIVTYTRIYRIAQKQIRRIAALERAAVHAKNCQTTTGNGKPVECSQ } & 255 \\ \beta 2 A R & 201 & \text { IASSIVSFYVPLVIMVFVYSRVFQEAKRQLQKIDKSE-GRFHVQNLSQVEQDGRTGHGLR } & 259 \\ & & & \\ \text { D1DR } & 256 & \text { PESSFKMSFKRETKVLKTLSVIMGVFVCWLPFFILNCILPFCGSGETQPFCIDSNTFDV } & 315 \\ \beta 2 A R & 260 & \text { RSSKFCL---KEHKALKTLGIIMGTFTLCWLPFFIVNIVHVI------QDNLIRKEVYIL } & 310 \\ & & & \\ \text { D1DR } & 316 & \text { FVWFGWANSSLNPIIYAFNADFRKAFSTLLGCYR } 349 & \\ \beta 2 A R & 311 & \text { LNWIGYVNSGFNPLIYCRSPDFRIAFQELL-CLR } 343 & \end{array}$

\section{Supplementary Figure 1}


10uM SKF Flag-D1DR Nb6B9-GFP Golgi Marker

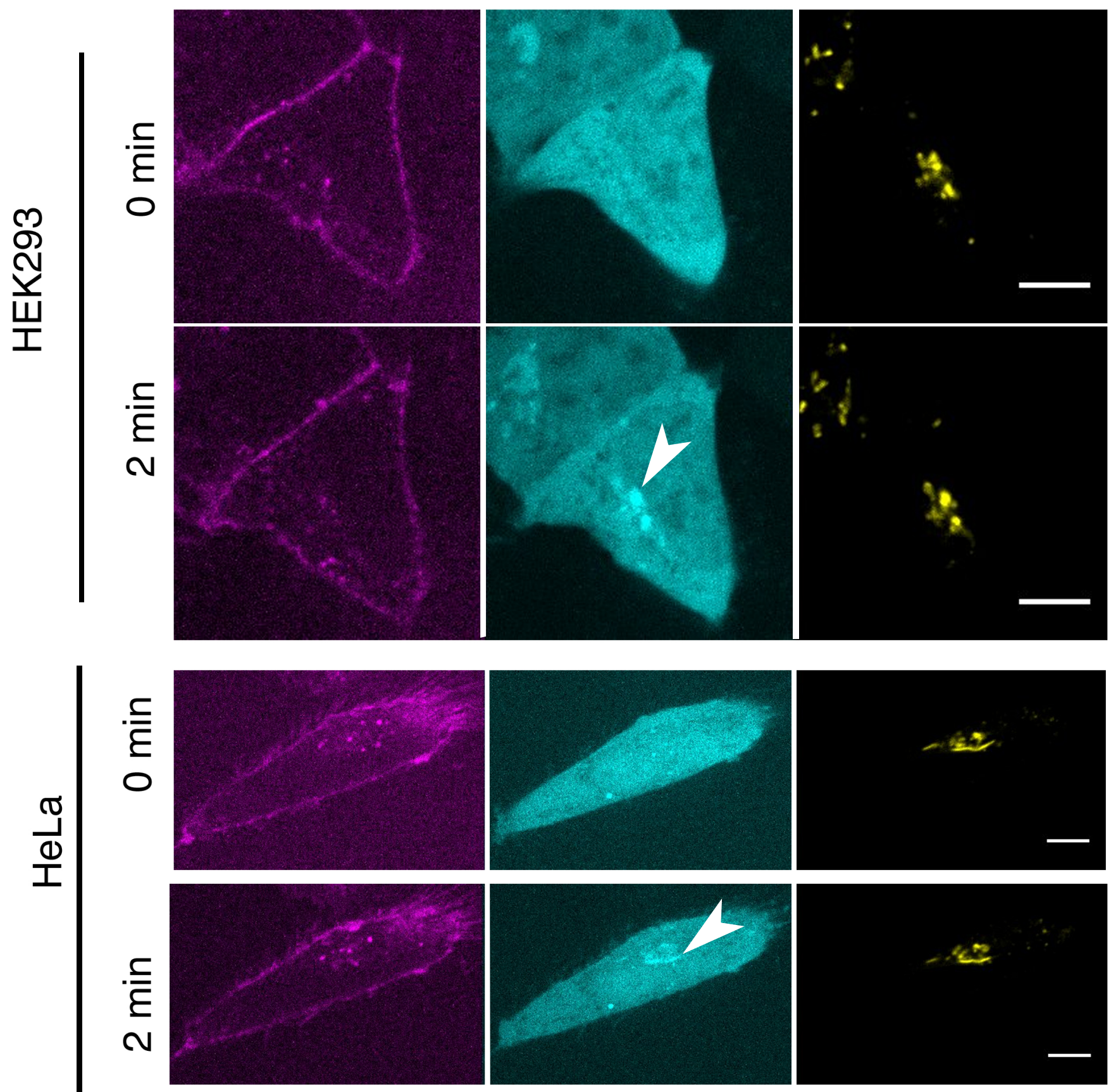

\section{Supplementary Figure 2}




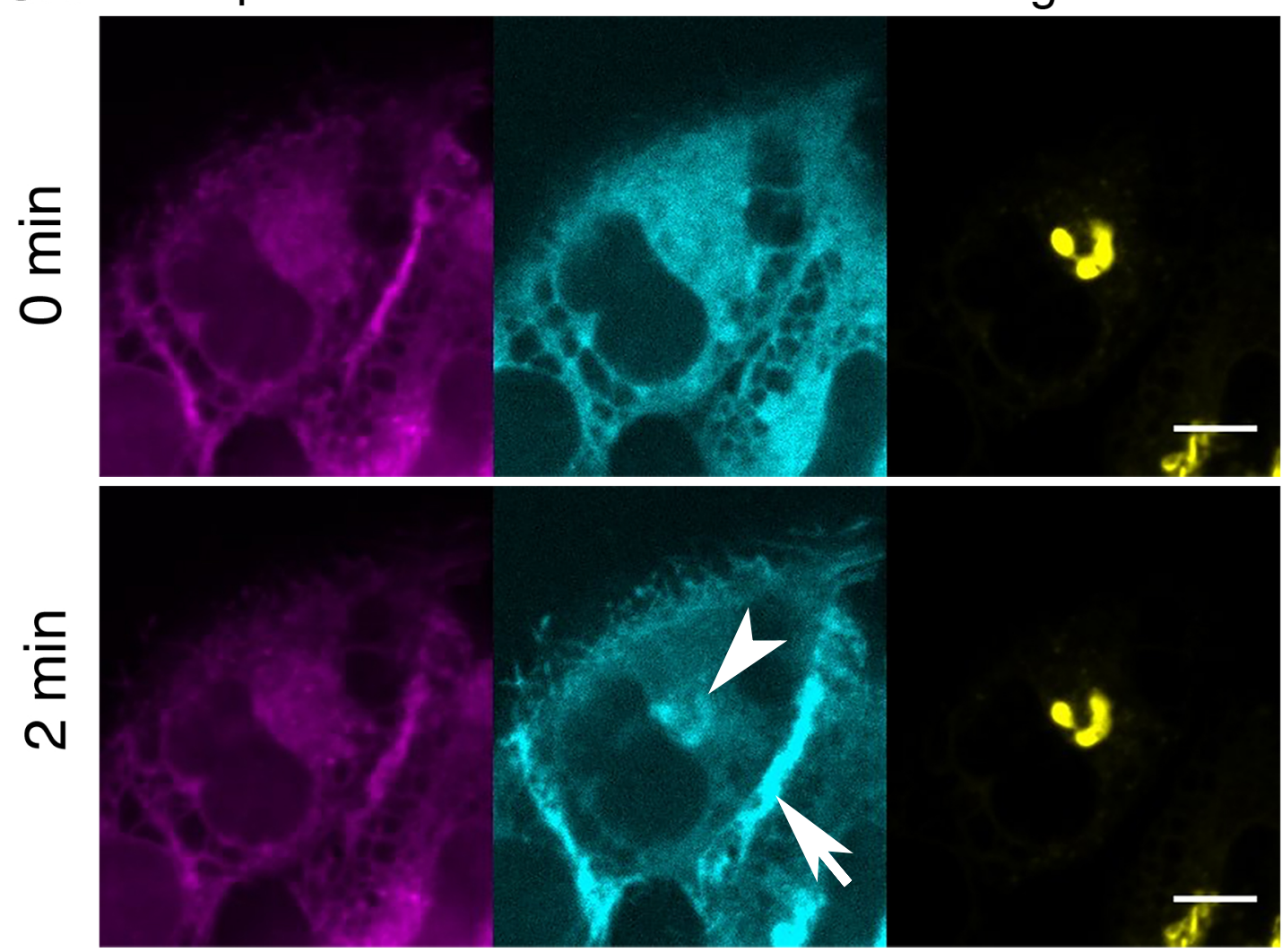

10nM DA Snap-D1DR miniGs-mVenus

Golgi Marker

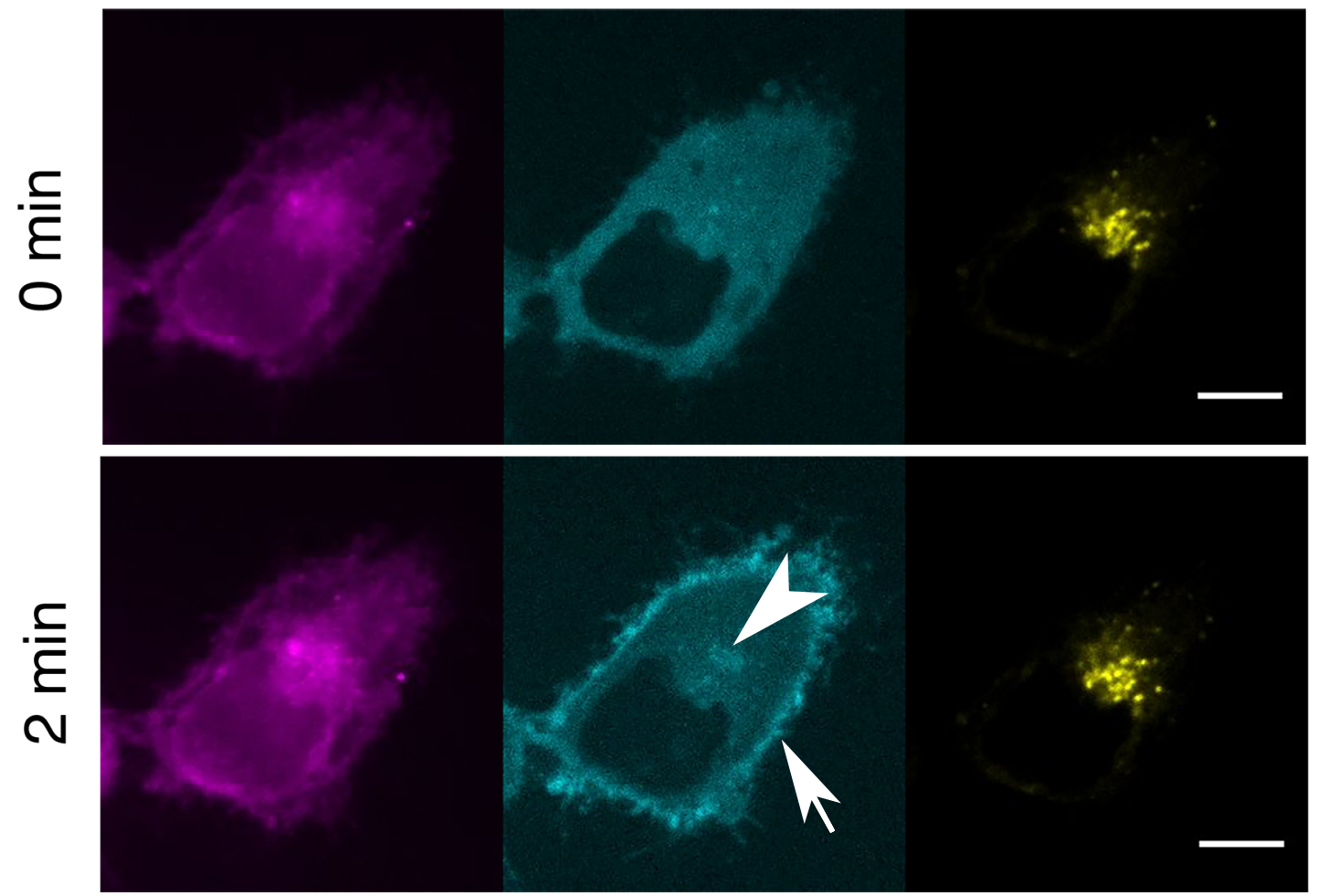


30 $\mu \mathrm{M}$ Dyngo4a $+10 \mu \mathrm{M}$ DA
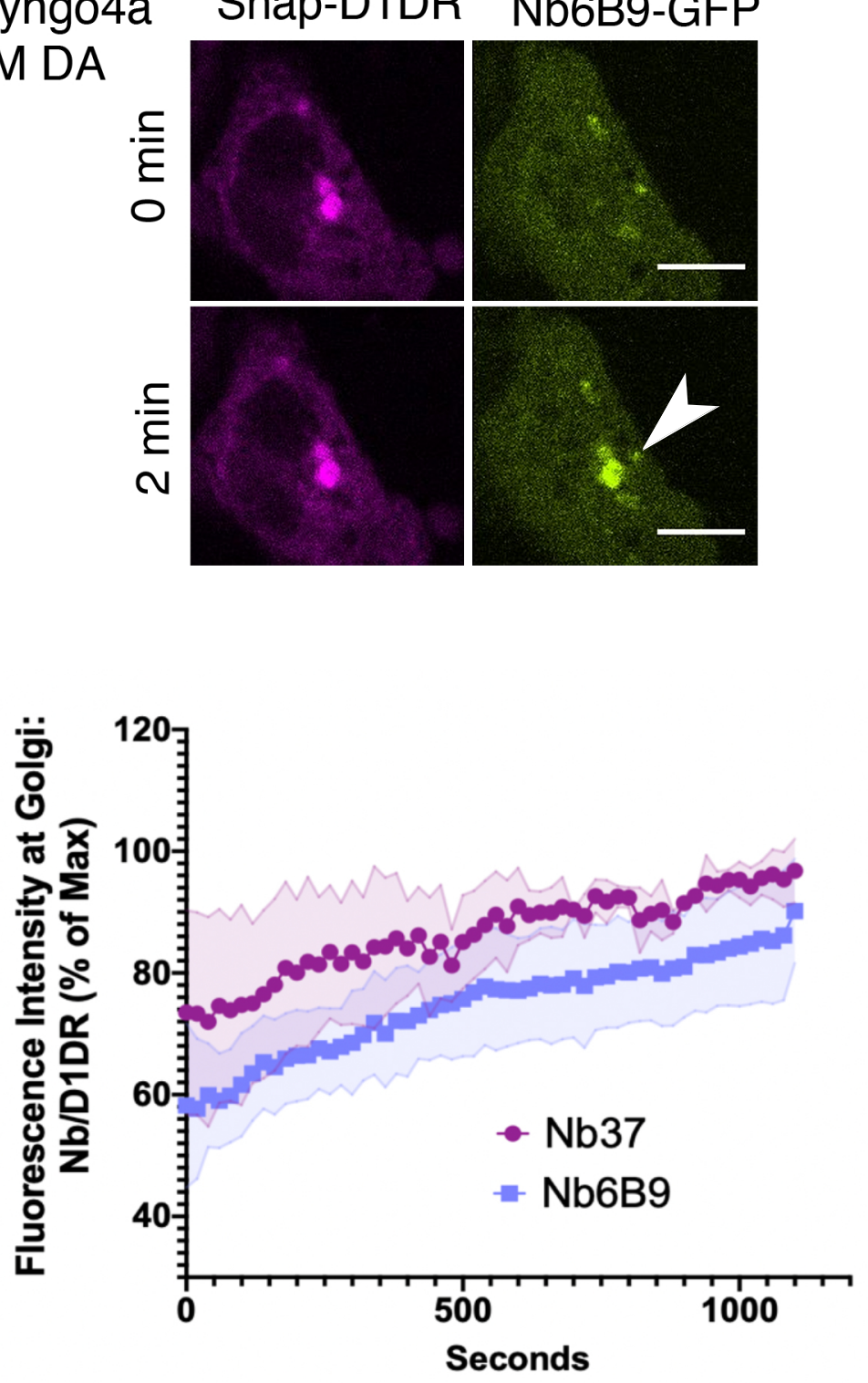

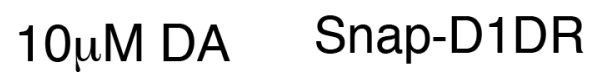

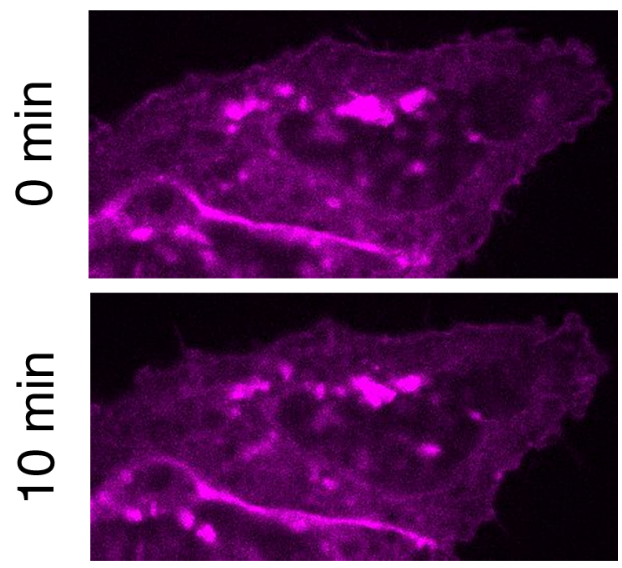

Nb37-GFP
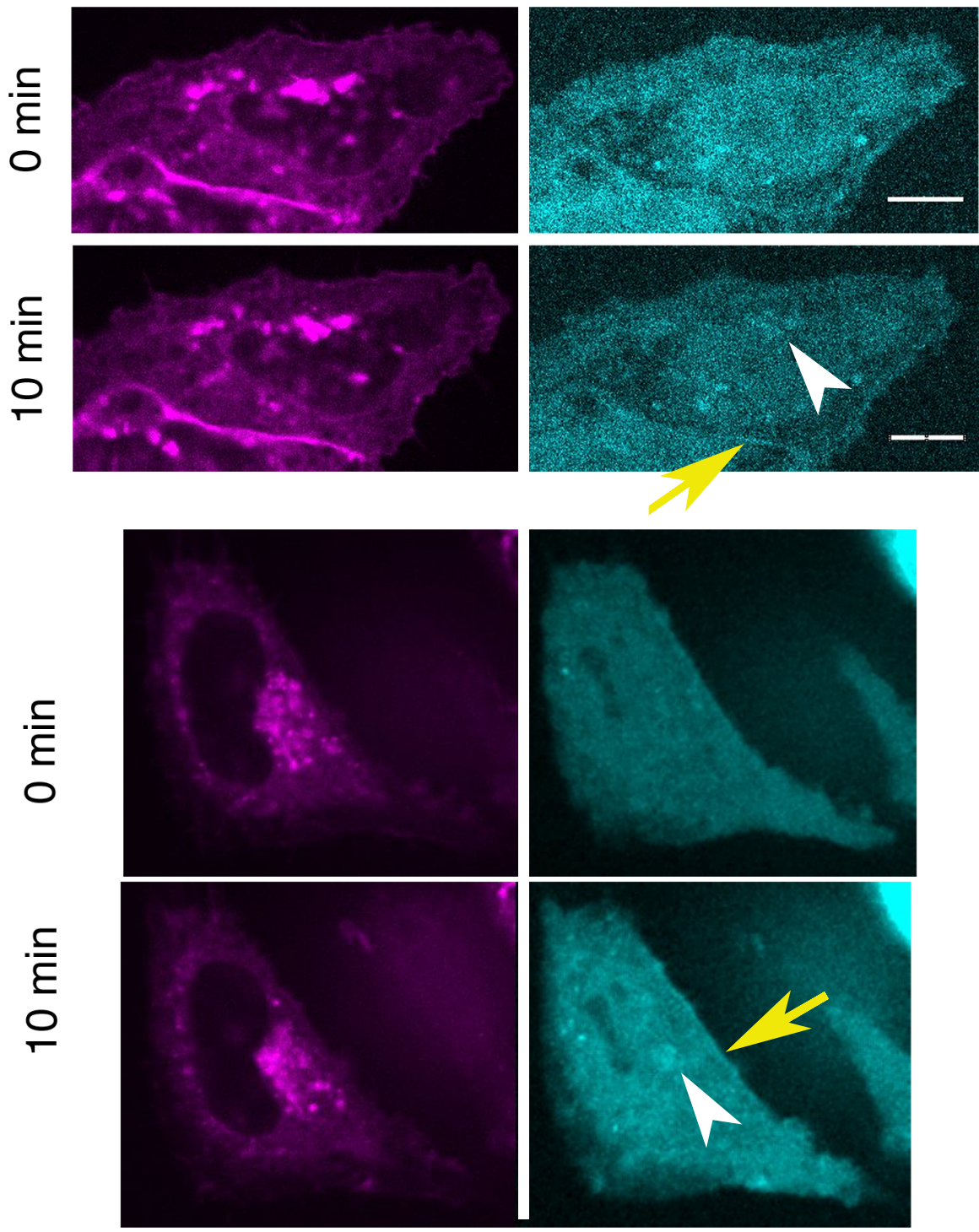

Supplementary Figure 4 

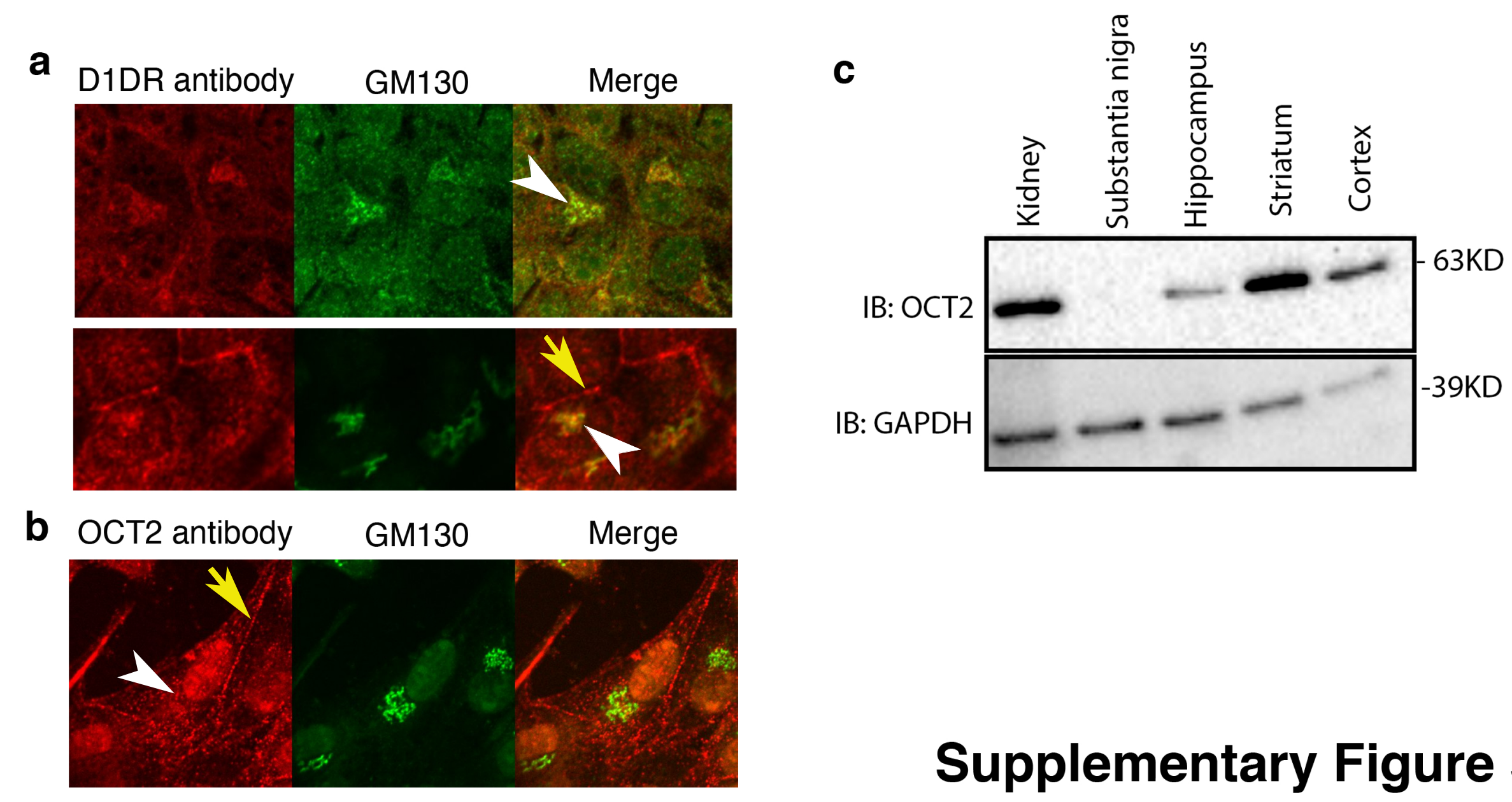

Supplementary Figure 5 


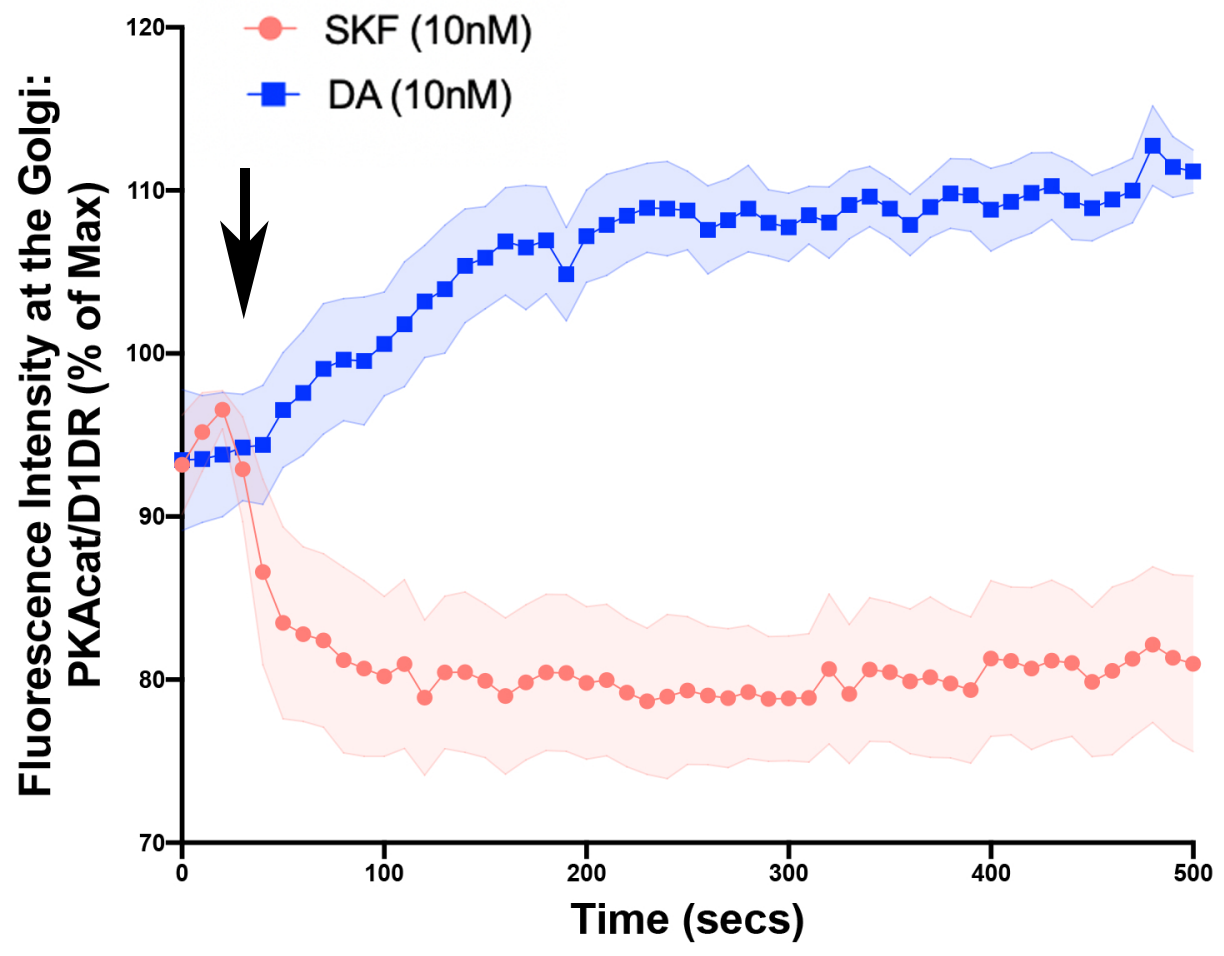

\section{Supplementary Figure 6}

